\title{
Galectin-3, a novel endogenous TREM2 ligand, detrimentally regulates inflammatory response in Alzheimer's disease
}

\author{
Antonio Boza-Serrano ${ }^{1}$ - $\cdot$ Rocío Ruiz ${ }^{2} \cdot$ Raquel Sanchez-Varo ${ }^{3,13} \cdot$ Juan García-Revilla ${ }^{2}$ Yiyi Yang ${ }^{1}$. \\ Itzia Jimenez-Ferrer ${ }^{11}$ - Agnes Paulus ${ }^{1} \cdot$ Malin Wennström ${ }^{5}$. Anna Vilalta ${ }^{4}$. David Allendorf ${ }^{4} \cdot$ Jose Carlos Davila $^{3,13}$. \\ John Stegmayr ${ }^{9} \cdot$ Sebastian Jiménez ${ }^{2,13} \cdot$ Maria A. Roca-Ceballos $^{2}$. Victoria Navarro-Garrido ${ }^{2,13} \cdot$ Maria Swanberg $^{11}$. \\ Christine L. Hsieh ${ }^{12}$. Luis M. Real ${ }^{7}$. Elisabet Englund ${ }^{8}$. Sara Linse ${ }^{6}$. Hakon Leffler ${ }^{9}$. Ulf J. Nilsson ${ }^{10}$. Guy C. Brown ${ }^{4}$. \\ Antonia Gutierrez $^{3,13} \cdot$ Javier Vitorica ${ }^{2,13} \cdot$ Jose Luis Venero ${ }^{2} \cdot$ Tomas Deierborg $^{1}$
}

Received: 23 November 2018 / Revised: 12 April 2019 / Accepted: 12 April 2019 / Published online: 20 April 2019

(c) The Author(s) 2019

\begin{abstract}
Alzheimer's disease (AD) is a progressive neurodegenerative disease in which the formation of extracellular aggregates of amyloid beta $(\mathrm{A} \beta$ ) peptide, fibrillary tangles of intraneuronal tau and microglial activation are major pathological hallmarks. One of the key molecules involved in microglial activation is galectin-3 (gal3), and we demonstrate here for the first time a key role of gal3 in AD pathology. Gal3 was highly upregulated in the brains of AD patients and 5xFAD (familial Alzheimer's disease) mice and found specifically expressed in microglia associated with A $\beta$ plaques. Single-nucleotide polymorphisms in the LGALS3 gene, which encodes gal3, were associated with an increased risk of AD. Gal3 deletion in 5xFAD mice attenuated microglia-associated immune responses, particularly those associated with TLR and TREM2/DAP12 signaling. In vitro data revealed that gal 3 was required to fully activate microglia in response to fibrillar $A \beta$. Gal 3 deletion decreased the $\mathrm{A} \beta$ burden in 5xFAD mice and improved cognitive behavior. Interestingly, a single intrahippocampal injection of gal3 along with $A \beta$ monomers in WT mice was sufficient to induce the formation of long-lasting ( 2 months) insoluble A $\beta$ aggregates, which were absent when gal3 was lacking. High-resolution microscopy (stochastic optical reconstruction microscopy) demonstrated close colocalization of gal3 and TREM2 in microglial processes, and a direct interaction was shown by a fluorescence anisotropy assay involving the gal3 carbohydrate recognition domain. Furthermore, gal3 was shown to stimulate TREM2-DAP12 signaling in a reporter cell line. Overall, our data support the view that gal3 inhibition may be a potential pharmacological approach to counteract AD.
\end{abstract}

Keywords Alzheimer's disease (AD) · Galectin-3 · TREM2 $\cdot$ Microglia $\cdot$ Inflammation $\cdot$ Amyloid aggregation

Electronic supplementary material The online version of this article (https://doi.org/10.1007/s00401-019-02013-z) contains supplementary material, which is available to authorized users.

Javier Vitorica, Jose Luis Venero and Tomas Deierborg shared senior authorship.

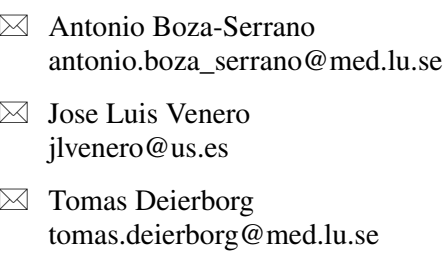

Antonio Boza-Serrano

antonio.boza_serrano@med.lu.se

$\triangle$ Jose Luis Venero

jlvenero@us.es

$\triangle$ Tomas Deierborg

tomas.deierborg@med.lu.se

Extended author information available on the last page of the article

\section{Introduction}

Alzheimer's disease (AD) is the leading cause of dementia, affecting more than 24 million people worldwide [4] and with the incidence of $\mathrm{AD}$ increasing dramatically as the global population ages. The classical hallmarks of $\mathrm{AD}$ include the formation of amyloid-beta $(\mathrm{A} \beta)$ plaque deposits and neurofibrillary tangles (NFT) containing abnormal hyperphosphorylation of tau. Over the course of the disease, the deposition of $A \beta$ and the formation of the NFTs appear to be correlated with the on-going hippocampal neurodegeneration [6]. Hippocampal neurodegeneration has a negative effect on the cognitive ability of patients, especially in the formation of new memories. The mechanisms triggering the deposition of the $\mathrm{A} \beta$ or the formation of NFTs are 
currently under investigation. However, several mechanisms and factors have been suggested to be involved in the initiation and the progression of the disease, including activation of the innate immune system, environmental factors and lifestyle [42]. The innate immune system has been widely studied and has been implicated in several neurodegenerative diseases [19]. Over the last few years, several studies have suggested that inflammation plays a major role in the initiation and progression of $\operatorname{AD}[17,20,62,66]$.

The inflammatory process in the central nervous system (CNS) is generally referred to as neuroinflammation. Glial cells have a leading role in propagating neuroinflammation. Among glial cells, microglia are considered the main source of proinflammatory molecules within the brain [18, 27, 63]. It is believed that sustained release of proinflammatory molecules such as cytokines, chemokines, nitrogen reactive species (NRS) or reactive oxygen species (ROS) can create a neurotoxic environment that drives the progression of $\mathrm{AD}[1,19,46]$. Moreover, there is strong evidence supporting the role of inflammatory molecules, such as iNOS, in the initiation of plaque formation due to post-translational modifications of $A \beta$, leading to a faster aggregation $[31,32]$. Indeed, counteracting the aggregation process has been proposed as a therapeutic strategy to alleviate the progression of the pathology [58].

Conclusive evidence supporting a direct role of microglia in human neurodegeneration was revealed with the recent advent of massive genome analysis. Specifically, geneticassociated studies have identified several AD-risk genes strongly associated with the innate immune system, including, among others, triggering receptor on myeloid cells 2 (trem2), cd33, crl, clu, ephal and ms4a4a/ms4a6a [7, 16]. Recent single-cell transcriptomic studies of microglia have pointed out galectin-3 (Lgals3; gal3) as one of the most attractive molecules in brain innate immunity associated with neurodegeneration (see recent review [10]). Indeed, Holtman et al. [22] analyzed transcriptional profiles of isolated microglia from different disease mouse models, including $\mathrm{AD}$, amyotrophic lateral sclerosis and aging, and revealed a shared transcriptional network in all conditions, including a strong upregulation of gal3. Interestingly, the authors analyzed the most likely candidates to orchestrate the microglial activation phenotype and found four major hub genes: Lgals3, Igfl, Csfl and Axl [22]. Two other recent studies characterized the molecular signature of microglial cells associated with different disease conditions, including aging and $\mathrm{AD}[27,30]$. Again, a common microglial neurodegenerative disease-associated phenotype was identified, supporting that (1) the microglial phenotype was driven by TREM2 and (2) gal3 was one of the most upregulated genes.

Recent findings from our group have demonstrated that gal3 is released by LPS-treated microglia and acts as a ligand of toll-like receptor 4 (TLR4), which is one of the canonical receptors involved in the microglial inflammatory response [9]. Based on our previous studies and recent findings from the $\mathrm{AD}$ field related to the role of inflammation in the disease, we hypothesize that the reduction of microglial activation by removing/inhibiting gal 3 will counteract the inflammatory response present in $\mathrm{AD}$ and slow the progression of the disease. In this work, we demonstrate (1) a significant upregulation of gal3 in human AD patients compared to age-matched healthy controls, (2) the preferential expression of gal 3 in microglial cells in contact with $\mathrm{A} \beta$ plaques both in human and mouse, (3) a clear reduction of the inflammatory response in microglial cells challenged with $A \beta$ fibrils (fA $\beta$ ) following gal 3 inhibition and gal 3 deletion in microglial cultures, (4) a significant $A \beta$ plaque reduction and better cognitive outcome in 5xFAD mice lacking gal3, and (5) the role of gal3 as a ligand of TREM2 through its carbohydrate recognition domain (CRD) domain, which confers the ability to bind glycans.

\section{Materials and methods}

\section{Animals}

5xFAD-Ga13 KO transgenic mice were generated by crossing heterozygous $5 \times \mathrm{xFD}( \pm)$ mice with homozygous Gal3KO (-/-) mice to get 5xFAD $( \pm) / \mathrm{Gal} 3( \pm)$ mice. Subsequent crossings between animals expressing this genotype allowed for the generation of $5 \times \mathrm{xFA}( \pm)-\mathrm{Gal} 3(-/-)$ mice, hence referred to as 5xFAD/Gal3KO mice. 5xFAD/ Gal3 mice are hence referred to as 5xFAD mice. Male and female mice were equally distributed between the experimental groups. No differences were found between male and female mice in any of the experiments performed. All animal experiments were performed in accordance with the animal research regulations (RD53/2013 and 2010/63/UE) in Spain and European Union and with the approval of the Committee of Animal Research at the University of Seville (Spain).

For primary microglial cultures, Gal3KO mice with a C57BL/6 background were obtained from Dr. K. Sävman at Gothenburg University. All procedures were carried out in accordance with the international guidelines on experimental animal research and were approved by the Malmö-Lund Ethical Committee for Animal Research in Sweden (M25011, M30-16, Dnr 5.8.18-01107/2018).

\section{Genotyping}

The genotypes of Gal3-/- (KO) and Gal3+/+ (WT) mice were determined using an integrated extraction and amplification kit (Extract-N-Amp ${ }^{\mathrm{TM}}$, Sigma-Aldrich). First, the samples were incubated at $94{ }^{\circ} \mathrm{C}$ for $5 \mathrm{~min}$, followed by 40 cycles with denaturation at $94{ }^{\circ} \mathrm{C}$ for $45 \mathrm{~s}$, annealing at 
$55{ }^{\circ} \mathrm{C}$ for $30 \mathrm{~s}$, and elongation at $72{ }^{\circ} \mathrm{C}$ for $1.5 \mathrm{~min}$. The following primers (CyberGene, Solna, Sweden) were used: galectin-3 common (5'-CAC GAA CGT CTT TTG CTC TCT GG-3'), galectin-3-/- (5'-GCT TTT CTG GAT TCA TCG ACT GTG G-3', single band of $384 \mathrm{bp}$ ) and galectin-3+/+ (5'-TGA AAT ACT TAC CGA AAA GCT GTC TGC- $3^{\prime}$, single band of $300 \mathrm{bp}$ ) [17]. For the 5xFAD mice, the primers $\left(5^{\prime}-3^{\prime}\right)$ used are listed below: APP Forward AGGACTGACCACTCGACCAG, APP Reverse CGGGGG TCTAGTTCTGCAT, PSN1 Forward AATAGAGAACGG CAGGAGCA, PSN1 Reverse GCCATGAGGGCACTA ATCAT, WT APP Forward CTAGGCCACAGAATTGAA AGATCT, WTT APP Reverse GTAGGTGGAAATTCT AGCATCATCC, RD1, RD2 and RD3 AAGCTAGCTGCA GTAACGCCATTT ACCTGCATGTGAACCCAGTAT TCTATC, CTACAGCCCCTCTCCAAGGTTTATAG. The PCR products were labeled with SYBR ${ }^{\circledR}$ Green (SigmaAldrich), separated by gel electrophoresis and visualized using a CCD camera (SONY, Tokyo, Japan).

\section{Protein preparation}

$\mathrm{A} \beta$ (M1-42) (i.e., with a starting Met0 to allow for production of otherwise untagged peptide) was expressed in E. coli (BL21 DE3 PLysS Star) and purified from inclusion bodies after repeated sonication using ion exchange in batch mode and size exclusion chromatography in column format. This was followed by lyophylization of monomer aliquots. Each day, before use in any experiment, $A \beta 42$ monomer was again isolated from the aliquots by dissolving an aliquot in $1 \mathrm{~mL}$ of $6 \mathrm{M} \mathrm{GuHCl}$, and, using gel filtration (Superdex 75, 10-300 column) with $20 \mathrm{mM}$ sodium phosphate, $0.2 \mathrm{mM}$ EDTA, $\mathrm{pH} 8.0$ as running buffer, collected on ice in a low-binding tube (Genuine Axygen Quality, Microtubes, MCT-200-L-C, Union City, CA, USA). The concentration was determined by absorbance at $280 \mathrm{~nm}$ using $\varepsilon_{280}=1440 \mathrm{M}^{-1} \mathrm{~cm}^{-1}$. The solution was diluted with buffer and supplemented with concentrated $\mathrm{NaCl}$ to achieve $10 \mu \mathrm{M}$ monomer and $150 \mathrm{mM} \mathrm{NaCl}$. The solution was placed in wells of a PEGylated polystyrene plate (Corning 3881) and sealed with a plastic film to avoid evaporation. Thioflavin $\mathrm{T}$ (ThT) was added to one well from a concentrated stock to obtain $6 \mu \mathrm{M}$ ThT. Plates were incubated at $37{ }^{\circ} \mathrm{C}$ in a FLUOstar Omega plate reader under quiescent conditions (BMG Labtech, Offenburg, Germany), and the fibril formation of amyloid-beta was followed by reading the fluorescence (excitation $440 \mathrm{~nm}$, emission $480 \mathrm{~nm}$ ) through the bottom of the plate. The samples in wells without ThT were collected after reaching the plateau of the sigmoidal transition (after ca. $1 \mathrm{~h}$ ).

\section{Cryogenic transmission electron microscopy (cryo-TEM)}

Specimens for electron microscopy were prepared in a controlled environment vitrification system (CEVS) to ensure stable temperature and to avoid the loss of solution during sample preparation. The specimens were prepared as thin liquid films, $<300 \mathrm{~nm}$ thick, on lacey carbon-filmed copper grids and plunged into liquid ethane at $-180{ }^{\circ} \mathrm{C}$. This led to vitrified specimens, avoiding component segmentation and rearrangement and water crystallization, thereby preserving the original microstructures. The vitrified specimens were stored under liquid nitrogen until measured. An Oxford CT3500 cryoholder and its workstation were used to transfer the specimen into the electron microscope (Philips CM120 BioTWIN Cryo) equipped with a post-column energy filter (Gatan GIF100). The acceleration voltage was $120 \mathrm{kV}$. The images were recorded digitally with a CCD camera under low electron-dose conditions. The node-to-node distance was measured using the software Digital Graph (Gatan Inc.).

\section{Endotoxin test}

To further evaluate the properties of our protein preparation, we performed an endotoxin assay to ensure that BV2 microglial cell activation was not due to the presence of endotoxins such as LPS (suppl. Fig. 5, online resource 5). Fibril preparations used in the in vitro and in vivo experiments were tested for endotoxins using the Pierce ${ }^{\circledR} \mathrm{LAL}$ Chromogenic Endotoxin Quantitation Kit, (ThermoScientific) according to the manufacturer's instructions (suppl. Fig. 5a, online resource 5).

\section{XTT (cell viability) assay}

XTT assay was performed to measure mitochondrial activity (mitochondrial dehydrogenase) in living cells using XTT (2,3-bis-(2-methoxy-4-nitro-5-sulfophenyl)-2H-tetrazolium5-carboxyanilide salt) (Sigma-Aldrich, Sweden). The assay was performed following the manufacturer's protocol in a 96-well plate (Biochrom Asys Expert 96 micro plate reader, Cambridge, UK) (suppl. Fig. 5c, online resource 5).

\section{Cell lines and primary cultures}

BV2 microglial cells were cultured in 12-well plates, 250,000 cells/well and stimulated with $\mathrm{A} \beta$ monomers and fibrils for a range of time points $(3,6,12$ and $24 \mathrm{~h})$ and concentrations ( 3 and $10 \mu \mathrm{M}$ ). Primary microglial cells were obtained from WT and Gal3KO mice. The primary cells were obtained from the cortex, as previously described [15], and cultured for 14 days in T75 flask culture conditions before treatment. After 14 days, microglial cells were 
isolated, and 25,000 were cultured in 96-well plates and incubated for $12 \mathrm{~h}$ with $\mathrm{fA} \beta$. Cell viability and number of cells were assessed using a TC20 Bio-Rad Cell counter, BioRad chambers slides and trypan blue $0.04 \%$ for BV2 and primary cultures. The same number of viable cells of each genotype (WT or Gal3KO) was plated per well. The cells were grown in DMEM (Invitrogen), FBS (Invitrogen) 10\% (v/v) and penicillin-streptomycin (Invitrogen) $1 \%(\mathrm{v} / \mathrm{v})$ in $5 \% \mathrm{CO}_{2}$ in air at $37{ }^{\circ} \mathrm{C}$ in a humidified incubator. After incubation, the media was collected to measure extracellular cytokines and proteins to evaluate the microglial activation profile.

\section{TREM2-DAP12 reporter cell line}

The ability of gal 3 to activate TREM2-DAP12 signaling was assayed in a BWZ thymoma reporter cell line transfected with TREM2 and DAP12 as previously described [23]. In these cells, TREM2/DAP12 signaling activates phospholipase $\mathrm{C}$, leading to a calcium influx that activates calcineurin, which, in turn, leads to disinhibition of the nuclear import of NFAT (nuclear factor of activated T-cells). This, in turn, induces transcription of the LacZ $\beta$-galactosidase gene. The TREM2/DAP12 reporter cells or parental BWZ cells not expressing TREM2 or DAP12 (control) were incubated with the indicated concentrations of gal 3 for $24 \mathrm{~h}$ at $37^{\circ} \mathrm{C}$. Afterwards, they were washed and then lysed in a buffer containing $100 \mathrm{mM}$ 2-ME, $9 \mathrm{mM} \mathrm{MgCl}, 0.125 \%$ NP-40, and $30 \mathrm{mM}$ chlorophenol red galactosidase (CPRG). Plates were developed for $24 \mathrm{~h}$ at $37{ }^{\circ} \mathrm{C}$, and lacZ activity was measured as previously described [23]. As a positive control, ionomycin $(3 \mu \mathrm{M})$ was added.

\section{Phagocytosis experiments}

After $24 \mathrm{~h}$ of primary microglia culturing, $1 \mu \mathrm{M}$ of gal3 was added for $30 \mathrm{~min}$ prior to incubation or simultaneously with labeled A $\beta 1-42$ (HiLyte $^{\text {TM }}$ Fluor 647-labeled, Human; ANA64161) as monomers $(\mathrm{mA} \beta)$ or fibrils (fA $\beta)$ for $1 \mathrm{~h}$. fA $\beta$ samples were obtained by incubating them for $24 \mathrm{~h}$ at $37^{\circ} \mathrm{C}$. Cells were detached by brief incubation with trypsin with EDTA and analyzed by flow cytometry (Accuri C6, BD Biosciences). Mean fluorescence in the FL4 gate was used to plot results and is expressed as a percentage from $A \beta 1-42$ uptake into primary microglia.

\section{Sequential protein extraction}

Soluble and insoluble protein fractions were obtained from the whole cortex (mice) and temporal cortex (human) using sequential protein extraction. For each sample, fractions were obtained by homogenization of the cortex with a Dounce homogenizer in the presence of PBS $(1 \mathrm{~mL} / 100 \mu \mathrm{g}$ of tissue). The supernatant, the $\mathrm{S} 1$ fraction, was aliquoted and stored at $-80^{\circ} \mathrm{C}$. The $\mathrm{S} 1$ soluble fraction was obtained after centrifugation for $1 \mathrm{~h}$ at 40,000 rpm in special tubes for high-speed centrifugation by Beckman-Coulter. The pellet was dissolved in RIPA buffer (Sigma-Aldrich, Germany) and subsequently ultracentrifuged at $30,000 \mathrm{rpm}$. The resulting supernatant, the $\mathrm{S} 2$ fraction (intracellular particulate proteins), was aliquoted and stored. The pellet was re-dissolved in buffered-SDS (2\% SDS in $20 \mathrm{mM}$ Tris-HCl, $\mathrm{pH} 7.4$, $140 \mathrm{mM} \mathrm{NaCl}$ ) and then centrifuged as above. The supernatant, the $\mathrm{S} 3$ fraction (SDS releasable proteins), was stored. Finally, the remaining pellet (P3) was dissolved in SDS-urea (20 mM Tris- $\mathrm{HCl}, \mathrm{pH} 7.4,4 \%$ SDS and $8 \mathrm{M}$ urea). PBS and RIPA solution were prepared with a protein inhibitor (Protein Inhibitor Cocktail, ThermoScientific) to prevent protein degradation and to inhibit the enzymatic activity of phosphatases (PhosphoStop, Roche).

\section{Western blotting}

Proteins were extracted from cell cultures with RIPA buffer (Sigma-Aldrich, Germany) along with proteinase and phosphatase inhibitors (Roche, Switzerland). Protein concentration was measured using a BCA kit according to the manufacturer's protocol (BCA Protein Assay-Kit, ThermoScientific, Sweden). Protein extracts were then separated by SDS-PAGE using pre-cast gels (4-20\%, Bio-Rad) in TGS buffer (Bio-Rad, Sweden). The proteins were transferred to nitrocellulose membranes (Bio-Rad, Sweden) using the TransBlot Turbo system from Bio-Rad. The membranes were subsequently blocked for $1 \mathrm{~h}$ with skim milk at $3 \%$ $(\mathrm{w} / \mathrm{v})$ in PBS, then washed $3 \times 10 \mathrm{~min}$ in PBS supplemented with $0.1 \%$ (w/v) Tween 20 (PBS-T). Then, blots were incubated with primary antibodies in PBS-T, as mentioned above, overnight. Following this, we incubated the blots with secondary antibodies for $2 \mathrm{~h}$. After the secondary antibody, we washed three times with PBS-T, and then the blots were developed using ECL Clarity (Bio-Rad) according to the manufacturer's protocol and imaged using the ChemiBlot XRS+ system from Bio-Rad.

\section{ELISA plates}

MesoScale (MSD) plates were used to evaluate the cytokine levels (proinflammatory panels for IFN- $\gamma, \mathrm{IL}-1 \beta$, IL-2, IL-4, IL-5, IL-6, IL-8, IL-10, IL-12 and TNF- $\alpha$ ) in culture media and in blood- and brain-soluble fractions from both human and mouse samples. To measure the cytokines in mouse and human soluble fractions, we pulled together $50 \mu \mathrm{g}$ of the $\mathrm{S} 1$ and S2 fraction. MSD plates were also used to measure the levels of $A \beta 38 / 40 / 42$, phosphorylated tau and total tau in the soluble and insoluble fraction from the brain extract from WT, Gal3KO, 5xFAD and 5xFAD/Gal3KO mice. Serial 
dilutions of the soluble and insoluble fractions were tested to obtain an accurate measure of the protein levels. $1 \mu \mathrm{g}$ of protein from the soluble fraction was diluted to evaluate A $\beta 38 / 40 / 42$ levels, and $0.3 \mu \mathrm{g}$ of protein from the insoluble fraction was diluted to evaluate $A \beta 38 / 40 / 42$ levels. The plates were developed using the $4 \times$ reading buffer diluted to a factor of $1 \times$ with distilled water, and the plates were read using the QuickPlex Q120 reader from Mesoscale. The detection ranges of the different cytokines measured were as follows: IL1 $\beta$ (1670-0.408 pg/mL), IL4 (1660-0.405 pg/ $\mathrm{mL})$, IL12 (32,200-7.86 pg/mL), IL10 (3410-0.833 pg/mL), IFN- $\gamma$ (938-0.229 pg/mL), IL2 (2630-0.642 pg/mL), IL5 (967-0.236 pg/mL), IL6 (5720-1.40 pg/mL), KC/GRO (1980-0.483 pg/mL) and TNF- $\alpha(627-0.153 \mathrm{pg} / \mathrm{mL})$. The A $\beta 40$ detection range was $15,100-3.69 \mathrm{pg} / \mathrm{mL}$, and the $\mathrm{A} \beta 42$ detection range was $2280-0.557 \mathrm{pg} / \mathrm{mL}$. ELISA plates from R\&D (DY008 and DY1197-05) were used to measure the levels of gal3 (detection range 1000-15.6 pg/mL) in culture media. The protocol was carried out according to the manufacturer's protocol. FluoStar Optima reader (BMG Labtech) was used to read the gal3 assay.

\section{Immunohistochemistry and immunofluorescence}

\section{Immunohistochemistry}

Mice were transcardially perfused under deep anesthesia with $4 \%$ paraformaldehyde and $\mathrm{PBS}, \mathrm{pH}$ 7.4. The brains were removed, cryoprotected in sucrose and frozen in isopentane at $-15^{\circ} \mathrm{C}$. They were then cut in $40-\mu \mathrm{m}$ thick slices in the coronal plane on a freezing microtome. The slices were serially collected in wells containing cold PBS and $0.02 \%$ sodium azide. Free-floating sections from $5 x F A D$ and $5 \times \mathrm{xAD} / \mathrm{Gal} 3 \mathrm{KO}$ mice were first treated with $3 \% \mathrm{H}_{2} \mathrm{O}_{2} / 10 \%$ methanol in PBS, pH 7.4 for 20 min to inhibit endogenous peroxidases and then with an avidin-biotin blocking kit (Vector Labs, Burlingame, CA, USA) for 30 min to block endogenous avidin, biotin and biotin-binding proteins. For single immunolabeling, sections were immunoreacted with one of the following primary antibodies: anti-A $\beta 42$ rabbit polyclonal (1:5000 dilution, Abcam), anti-amyloid precursor protein (APP) rabbit polyclonal (1:20,000 dilution, Sigma), anti-CD45 rat monoclonal (clone IBL-3/16, 1:500 dilution, AbD Serotec), anti-galectin3 (gal3) goat polyclonal (1:3000 dilution, R\&D) over 24 or $48 \mathrm{~h}$ at room temperature. The tissue-bound primary antibody was detected by incubating for $1 \mathrm{~h}$ with the corresponding biotinylated secondary antibody (1:500 dilution, Vector Laboratories) and then followed by incubating for $90 \mathrm{~min}$ with streptavidin-conjugated horseradish peroxidase (Sigma-Aldrich) (dilution 1:2000). The peroxidase reaction was visualized with $0.05 \%$ 3-3-diaminobenzidine tetrahydrochloride (DAB, Sigma-Aldrich), $0.03 \%$ nickel ammonium sulfate and $0.01 \%$ hydrogen peroxide in PBS. After using DAB, some sections immunolabeled for APP, CD45 or gal3 were incubated for $3 \mathrm{~min}$ in a solution of $0.2 \%$ of Congo red. Sections were mounted on gelatine-coated slides, air-dried, dehydrated in graded ethanol, cleared in xylene and covered with DPX (BDH) mounting medium, omitting the primary antisera controlled for specificity of the immune reactions.

\section{Immunofluorescence}

For immunofluorescence, free-floating sections were first incubated with primary antibody followed by the corresponding Alexa secondary antibody (1:500 dilution, Invitrogen). Sections were embedded in autofluorescence eliminator reagent (Merck Millipore), following the manufacturer's recommendations, to eliminate fluorescence emitted by intracellular lipofuscin accumulation. Tissue was incubated with the specific primary antibody for $24 \mathrm{~h}$, and, the following day, the brain sections were rinsed for $1 \mathrm{~h}$ in PBS containing $0.1 \%$ Triton X-100. After incubating for $1 \mathrm{~h}$ with the corresponding secondary antibody (1:500, Alexa antibodies, Invitrogen), the sections were rinsed again with PBS containing $0.1 \%$ Triton $\mathrm{X}-100$ for $60 \mathrm{~min}$. Then, brain sections were mounted in glycerol $50 \%$ for visualization. For staining with thioflavin-S (Sigma-Aldrich), sections were first washed in PBS containing 0.1\% Triton X-100 and then incubated for $5 \mathrm{~min}$ with $0.5 \%$ thioflavin-S. Next, we washed the sections for $5 \times 10 \mathrm{~min}$ in PBS containing $0.1 \%$ Triton $\mathrm{X}-100$. The brain sections were mounted in glycerol $50 \%$ for visualization. The fixed tissue was examined in a confocal laser microscope (Leica SP5 II), under a Olympus BX-61 epifluorescent microscope and in an inverted ZEISS LSM 7 DUO confocal laser-scanning microscope using a 20x air objective with a numerical aperture of 0.5. All images were obtained under similar conditions (laser intensities and photomultiplier voltages) and usually on the same day. Morphometric analysis of the fluorescently labeled structures was performed offline with Fiji ImageJ software (W. Rasband, National Institutes of Health). Areas for the specific antibodies were determined automatically by defining outline masks based on brightness thresholds from maximal projected confocal images [3]. Finally, the phagosome area and the circularity of plaques (suppl. Fig. 6c, d, online resource 6) were measured as described previously [65].

\section{Plaque loading quantification}

Plaque loading was defined as the percentage of hippocampal CA1 region stained for $\mathrm{A} \beta$ (with anti-A $\beta 42$ ). Quantification of extracellular $A \beta$ content in neurites was done as previously described $[51,55]$. Images were acquired with a Nikon DS-5 M high-resolution digital camera connected to a Nikon Eclipse $80 \mathrm{i}$ microscope. The camera settings 
were adjusted at the start of the experiment and maintained for uniformity. Digital $4 \times$ (plaques) images from 6- and 18-month-old 5xFAD and 5xFAD/Gal3KO mice (4 sections/ mouse; $n=6-7 /$ age/genotype) were analyzed using Visilog 6.3 analysis program (Noesis, France). The hippocampal area (CA1 or thalamus) in each image was manually outlined, leaving out the pyramidal and granular layers in the case of APP quantification. Then, plaque areas within the hippocampal regions were identified by level threshold that was maintained throughout the experiment for uniformity. The color images were converted to binary images with plaques. The loading (\%) for each transgenic mouse was estimated and defined as (sum plaque area measured/sum hippocampal area analyzed) $\times 100$. The sums were taken over all slides sampled, and a single burden was computed for each mouse. The mean and standard deviation (SD) of the loadings were determined using all the available data. Quantitative comparisons were carried out on sections processed at the same time with the same batches of solutions.

\section{Hippocampal $A \beta$ injections in wild-type mice}

$A \beta$ monomers $(10 \mu \mathrm{M})$ and $A \beta$ monomers together with gal3 $(10 \mu \mathrm{M})$ were pre-incubated for $1 \mathrm{~h}$ at $37{ }^{\circ} \mathrm{C}$ prior to the intracerebral injections. A volume of $2 \mu \mathrm{l}$ was injected $(0.5 \mu \mathrm{l} / \mathrm{min})$ in the dentate gyrus. In the left hemisphere, we injected only $A \beta$ monomers, and, in the right hemisphere, we injected $A \beta$ monomers with gal3. Two months after injections, the mice were sacrificed and transcardially perfused with $4 \%$ PFA. The brains were postfixed in $4 \%$ PFA overnight followed by sucrose saturation (25\% in PBS). Brains were sectioned by a microtome $(30 \mu \mathrm{m})$ and stained for ThioS, 6E10, GFAP, NeuN and Iba1.

\section{Stochastic optical reconstruction microscopy (STORM)}

The samples were the same that we used for the confocal images (see the protocol in immunofluorescence staining section in the "Materials and methods" section), except that we changed the buffer and the detection device. Images were acquired as previously described by Van der Zwaag et al. [56]. Briefly, images were acquired using a Nikon $\mathrm{N}$-STORM system configured for total internal reflection fluorescence (TIRF) imaging. STORM buffer contains $10 \mathrm{mM}$ Tris $\mathrm{pH} 8,50 \mathrm{mM} \mathrm{NaCl}$ an oxygen scavenging system $(0.5 \mathrm{mg} / \mathrm{mL}$ glucose oxidase, Sigma-Aldrich), $34 \mu \mathrm{g} / \mathrm{mL}$ catalase (Sigma), 5\% (w/v) glucose and $100 \mathrm{mM}$ cysteamine (Sigma-Aldrich). Excitation inclination was tuned to adjust the focus and to maximize the signal-to-noise ratio. Fluorophores were excited by illuminating the sample with the $647 \mathrm{~nm}(\sim 125 \mathrm{~mW})$ and $488 \mathrm{~nm}(\sim 50 \mathrm{~mW})$ laser lines built into the microscope. Fluorescence was detected by means of a Nikon APO TIRF $100 \times / 1.49$ Oil W.D. $0.12 \mathrm{~mm}$. Images were recorded onto a $256 \times 256$ pixel region of a EMCCD camera (Andor Ixon3 897). Single-molecule localization movies were analyzed with NIS element Nikon software.

\section{Immunofluorescence of human sections}

Endogenous peroxidases were deactivated by incubating the samples in a peroxidase block for $15 \mathrm{~min}$ with gentle agitation. The sections were then washed $(3 \times 15 \mathrm{~min})$ in $0.1 \mathrm{M}$ KPBS, after which they were incubated in blocking buffer (5\% goat serum blocking with $0.1 \mathrm{M}$ KPBS and $0.025 \%$ Triton-X) for at least $1 \mathrm{~h}$ with gentle agitation. The sections were then washed $(3 \times 15 \mathrm{~min})$ in $0.1 \mathrm{M} \mathrm{KPBS}$, and the primary antibody was added (1:300). The sections were then incubated at $4{ }^{\circ} \mathrm{C}$ overnight with gentle agitation. The sections were washed $(3 \times 15 \mathrm{~min})$ in $0.1 \mathrm{M} \mathrm{KPBS}$, after which poly-HRP secondary antibody was added. The sections were then incubated for $1 \mathrm{~h}$ at room temperature. For triple Iba1/ gal3/A $\beta$ immunofluorescence, sections were first incubated with the primary antibodies followed by the corresponding Alexa 647/488/555 secondary antibodies (1:1000 dilution, AlexaFluor, Life Technologies). Sections were embedded in 0.6 g Sudan Black (Sigma) dissolved in 70\% ethanol. The sections, after mounting and drying on slides, were incubated in the sudden black solution for $5 \mathrm{~min}$. Subsequently, the sections were washed in PBS and mounted with mounting medium. The camera settings were adjusted at the start of the experiment and maintained for uniformity. A Nikon Eclipse Ti confocal microscope (Nikon, Japan) and NIS elements software (Nikon, Japan) were used to take 20x magnification pictures and for the final collage.

\section{Fluorescent anisotropy}

\section{Production of recombinant human galectins}

Recombinant human galectins (i.e., gal3 wild-type and gal3 R186S mutant) were produced in E. coli BL21 Star (DE3) cells and purified by affinity chromatography on lactosylsepharose columns, which has been previously described by Salomonsson et al. [49].

\section{Establishment of the affinity between galectins and TREM2}

A fluorescence anisotropy (FA) assay was used to determine the affinity of recombinant TREM2 for wild-type or mutant gal3 in solution. The method has previously been described in detail by Sörme et al. for saccharides and synthetic smallmolecule galectin inhibitors [53]. In short, increasing concentrations of galectins are first tittered against a fixed concentration of saccharide probe $(0.02 \mu \mathrm{M})$. When this is done, the anisotropy value increases from a value when probe is 
free in solution $\left(A_{0}\right)$ to a value when all probe molecules are bound to galectins $\left(A_{\max }\right)$. To establish the dissociation constant $\left(K_{\mathrm{d}}\right)$ values between TREM2 and gal3 wild-type or R186S mutant, a competitive variant of the FA assay was used. In this assay, increasing concentrations of TREM2 were tittered against fixed concentrations of galectin and probe (see below for details). By obtaining the anisotropy values for the different TREM 2 concentrations, together with the values for $A_{\max }$ and $A_{0}$, the $K_{\mathrm{d}}$ values could be calculated according to the equations presented in Sörme et al. [53].

The FA of the fluorescein-conjugated probes was measured using a PheraStarFS plate reader and PHERAstar Mars version 2.10 R3 software (BMG, Offenburg, Germany). The excitation wavelength used was $485 \mathrm{~nm}$, and the emission was read at $520 \mathrm{~nm}$. All experiments were performed in PBS at room temperature $\left(\sim 20^{\circ} \mathrm{C}\right)$. The anisotropy values for each data point were read in duplicate wells of 386-well plates (at a total volume of $20 \mu \mathrm{l}$ ). $K_{\mathrm{d}}$ values were calculated as weighted mean values from concentrations of TREM2 that generated between 20 and $80 \%$ inhibition, where inhibition values of approximately $50 \%$ had the highest impact on the mean value.

Gal3 (wild type) affinities Experiments were performed with gal 3 at a concentration of $0.30 \mu \mathrm{M}$ and the fluorescent probe 3,3'-dideoxy-3-[4-(fluorescein-5-ylcarbonylaminomethyl)-1H-1,2,3-triazol-1-yl]-3'-(3,5dimethoxybenzamido)-1,1'-sulfanediyl-di- $\beta$-D-galactopyranoside at $0.02 \mu \mathrm{M}[50]$.

Gal3 (R186S mutant) affinities Experiments were performed with gal3 R186S at a concentration of $2 \mu \mathrm{M}$ and the fluorescent probe 2-(fluorescein-5/6-yl-carbonyl)aminoethyl-2-acetamido-2-deoxy- $\alpha$-D-galactopyranosyl-(1-3)[ $\alpha$-L-fucopyranosyl-(1-2)]- $\beta$-D-galactopyranosyl-(1-4)- $\beta$-Dglucopyranoside at $0.02 \mu \mathrm{M}$ [13].

\section{TREM2 and galectin-3 3D modeling}

The extracellular domain of TREM2 (white) with tetratennary $\mathrm{N}$-glycan (stick-model) and gal3 CRD (yellow) was modeled. Mutations in TREM2 leading to an increased risk of $\mathrm{AD}$ are blue, and those leading to Nasu-Hakola disease (NHD) are red. The C-terminus of the extracellular fragment that normally links further to the transmembrane domain is green (suppl. Fig. 7c).

The TREM2 model is from pdb 5 ELI, which was published by Ref. [29].

A tetranatennary $\mathrm{N}$-glycan was modeled in at the single N-glycosylation site using the GlyCam server, Woods Group (2005-2018) GLYCAM Web. Complex Carbohydrate Research Center, University of Georgia, Athens, GA, USA (http://glycam.org). The model of bound gal3 CRD was from a structure in complex with LacNAc (pdb IKJL, [52], which was superimposed on the terminal LacNAc of the N-glycan.
The picture was made with The PyMOL Molecular Graphics System, Version 2.0 Schrödinger, LLC.

\section{Gene array}

Hippocampal samples from 5xFAD, 5xFAD/Gal3KO, WT and Gal3KO mice at 6 and 18 months were collected and snap-frozen in dry ice to carry out the mRNA evaluation. mRNA was extracted using the RNAeasy Mini Kit (Qiagen) according to the manufacturer's protocol. The extraction was performed automatically using the QIAcube device from Qiagen. RNA concentration was subsequently quantified using a NanoDrop 2000C. Samples with a RIN value under 8.7 were not included. cDNA synthesis was performed using Superscript Vilo cDNA Synthesis (ThermoScientific) according to the manufacturer's protocol. TaqMan ${ }^{\circledR}$ OpenArray ${ }^{\circledR}$ Mouse Inflammation, TaqMan ${ }^{\circledR}$ OpenArray ${ }^{\circledR}$ Real-Time PCR Master and TaqMan ${ }^{\circledR}$ OpenArray ${ }^{\circledR}$ RealTime PCR were used to perform the qPCR. Real-Time PCR Open Array from Applied Biosystems was used to read the Open Array 384-well plates, which were used to perform the qPCR.

\section{Gene array analysis}

Differently expressed genes were identified using the data from the HTqPCR assay assessed in the Openarray platform (Qiagen). Statistical analysis was performed using the software DataAssist v3.01. The maximum CT permitted was 35 . First, we sorted the data based on the gene fold change and then we converted the data to Log2FC. We compared 5xFAD mice at 6 and 18 months to WT mice and also compared the $5 \mathrm{xFAD}$ mice with the $5 \mathrm{xFAD}$ Gal3KO mice at 6 and 18 months. We selected genes with a Log2FC value between \pm 2 at 6 months and \pm 4 at 18 months. Out of 629 genes, 95 were selected at 6 months and 106 genes at 18 months. For the analysis of the main pathways affected by the lack of gal3 at 6 and 18 months in our 5xFAD mouse model, we used network analysis along with KEGG and the Reactome database.

\section{Behavioral tests}

The Morris water maze test tests spatial acquisition memory and was conducted in a pool consisting of a circular tank (180 cm diameter) filled with opaque water at $20^{\circ} \mathrm{C} \pm 1{ }^{\circ} \mathrm{C}$. A platform $(15 \mathrm{~cm}$ diameter) was submerged $10 \mathrm{~mm}$ under the water surface. A white curtain with specific distal visual cues surrounded the water maze. White noise was produced from a radio centrally positioned above the pool to avoid the use of auditory cues for navigation. Spatial learning sessions were conducted over ten consecutive days with four trials per day. Each trial was started by introducing the mouse, facing 
the pool wall, at one of four starting points in a quasi-random fashion to prevent strategy learning. Each mouse remained on the platform for $30 \mathrm{~s}$ before transfer to a heated waiting cage. During all acquisition trials, the platform remained in the same position. On the day following the last learning trial, a $60 \mathrm{~s}$ probe test was conducted, during which the platform was removed from the pool. All mouse movements were recorded using a computerized tracking system that calculated distances moved and latencies required for reaching the platform (ANY-maze 5.2).

\section{Total RNA extraction and qPCR}

Total RNA and proteins were extracted using TriPure Isolation Reagent (Roche). RNA integrity (RIN) was determined using RNA Nano 6000 (Agilent). The RIN was $8.5 \pm 0.5$. RNA was quantified using a NanoDrop 2000 spectrophotometer (ThermoFischer, Spain).

\section{Retrotranscription and quantitative real-time RT-PCR}

Retrotranscription (RT) ( $4 \mu \mathrm{g}$ of total RNA) was performed with the High-Capacity cDNA Archive Kit (Applied Biosystems). For real-time qPCR, $40 \mathrm{ng}$ of cDNA was mixed with $2 \times$ Taqman Universal Master Mix (Applied Biosystems) and 20x Taqman Gene Expression assay probes (Applied Biosystems, supplemental). Quantitative PCR reactions (qPCR) were done using an ABI Prism 7900HT (Applied Biosystems). The cDNA levels were determined using GAPDH as the housekeeping gene. Results were expressed using the comparative double-delta $C_{\mathrm{t}}$ method $\left(2^{-\Delta \Delta C_{\mathrm{t}}}\right) . \Delta C_{\mathrm{t}}$ values represent GAPDH normalized expression levels. $\Delta \Delta C_{\mathrm{t}}$ was calculated using 6-month-old WT mice samples.

\section{Taqman probes}

Iba1 (Ref. Mm00479862_g1), CD45 (Ref. Mm01293577_ m1), CD68 (Ref. Mm03047343_m1), TREM2 (Ref. Mm04209424_g1), Cx3Cr1 (Ref. Mm02620111_s1), GAPDH (Ref. Mm99999915_g1), IL-6 (Ref. Mm00446190_ m1), TNFa (Ref. Mm00443258_m1), GFAP (Ref. Mm01253033_m1).

\section{Genetic association analysis}

\section{Datasets}

Genotypic datasets from four genome-wide association studies (GWAS) were used in this study: (a) the Murcia study [2]; (b) the Alzheimer's Disease Neuroimaging Initiative (ADNI) study [41]; (c) the GenADA study [36]; and (d) the NIA study [60] (for GWAS dataset details, see supplementary information). The Murcia study was previously performed by researchers from our group. Datasets from the ADNI, GenADA, and NIA studies were obtained from dbGAP (http://www.ncbi.nlm.nih.gov/gap), Coriell Biorepositories (http://www.coriell.org/) or ADNI (http:// adni.loni.ucla.edu/). Prior to the genetic association analysis, each dataset (Murcia, ADNI, GenADA, NIA and TGEN) was subjected to both an extensive quality control analysis and a principal component analysis. In addition, since different platforms were used in the five GWAS analyzed, we imputed genotypes using HapMap phase 2 CEU founders $(n=60)$ as the reference panel. This approach has been previously described $[2,8,37]$. Overall, a total of 2252 cases and 2538 controls were included in the meta-analysis.

\section{SNP selection}

To select single-nucleotide polymorphisms (SNPs) within the LGALS3 gene, including $1000 \mathrm{pb}$ upstream and downstream of that genetic region, we used the UCSC Table Browser data retrieval tool [26], release genome assembly: Mar. 2006 (NCBI36/hg 18), from the UCSC Genome Browser database (http://genome.ucsc.edu/) [21]. Selected SNPs were extracted from GWAS datasets using Plink v1.06 software [47].

\section{Linkage disequilibrium blocks}

Linkage disequilibrium (LD) blocks were determined along the genomic regions studied using Haploview software [5] and genotyping data from the largest dataset used (NIA dataset).

\section{Association analyses}

Unadjusted single-locus allelic ( $1 d f)$ association analysis within each independent GWAS dataset was carried out using Plink software. We combined data from these four GWAS datasets using the meta-analysis tool in Plink selecting only those markers common to, at least, three studies. For all single-locus meta-analyses, fixed effect models were employed when no evidence of heterogeneity was found, otherwise random effect models were employed.

All selected SNPs were located close to 3 'end of the $L G A L S 3$ gene. Because all SNPs belonged to the same linkage disequilibrium block, multiple test correction was not applied. Thus, the $p$ value threshold was established as 0.05 .

\section{Supplementary information regarding the GWAS datasets used}

The Murcia study was designed as a new case-control GWAS of the Spanish population. In this study, 1128 
individuals were genotyped using an Affymetrix NspI 250K chip. A sample of 327 sporadic Alzheimer's disease (AD) patients diagnosed as possible or probable AD in accordance with NINCDS-ADRDA criteria by neurologists at the Virgen de Arrixaca University Hospital in Murcia (Spain) and 801 controls with unknown cognitive status from the Spanish general population were included. The Alzheimer's Disease Neuroimaging Initiative (ADNI) longitudinal study was launched in 2003 by the National Institute on Aging (NIA), the National Institute of Biomedical Imaging and Bioengineering (NIBIB), the Food and Drug Administration (FDA), private pharmaceutical companies and nonprofit organizations as a $\$ 60$ million, 5-year public-private partnership. The primary goal of ADNI has been to test whether serial magnetic resonance imaging, positron emission tomography, other biological markers and clinical and neuropsychological assessment can be combined to measure the progression of mild cognitive impairment (MCI) and early AD. Determination of sensitive and specific markers of very early $\mathrm{AD}$ progression is intended to aid researchers and clinicians in developing new treatments and monitoring their effectiveness, as well as to lessen the time and cost of clinical trials. The principal investigator of this initiative is Michael W. Weiner, MD, VA Medical Center and University of California, San Francisco. ADNI is the result of efforts of many co-investigators from a broad range of academic institutions and private corporations, and subjects have been recruited from over 50 sites across the US and Canada. The initial goal of ADNI was to recruit 800 adults, aged 55-90, to participate in the research, approximately 200 cognitively normal older individuals to be followed for 3 years, 400 people with MCI to be followed for 3 years and 200 people with early $\mathrm{AD}$ to be followed for 2 years. For up-to-date information, see http://www.adni-info.org. The GenADA study included 801 cases that met the NINCDS-ADRDA and DSM-IV criteria for probable AD and 776 control subjects without a family history of dementia that were genotyped using the Affymetrix 500K GeneChip Array set. The NIA Genetic Consortium for Late Onset Alzheimer's Disease (LOAD) study originally included 1985 cases and 2059 controls genotyped with the Illumina Human 610Quad platform. Using family trees provided in the study, we excluded all related controls and kept one case per family, resulting in a total of 1077 cases and 876 controls.

Some data used in preparation of this article were obtained from the Alzheimer's disease neuroimaging initiative (ADNI) database (http://adni.loni.ucla.edu/). As such, the investigators within the ADNI contributed to the design and implementation of ADNI and/or provided data but did not participate in analysis or writing of this report. A complete listing of ADNI investigators can be found at https ://adni.loni.usc.edu/wp-content/uploads/how_to_apply/ ADNI_Acknowledgement_List.pdf.

\section{Human material}

All the human material used was obtained from the Lund University Hospital, Neuropathology Unit (suppl. Table 1, online resource 8; Elisabet Englund, elisabet.englund@ med.lu.se) and The Netherlands Institute for Neuroscience, Amsterdam, The Netherlands (Inge Huitinga, i.huitinga@ nin.knaw.nl; suppl. Table 2, online resource 9). Written informed consent for the use of brain tissue and clinical data for research purposes was obtained from all patients or their next of kin in accordance with the International Declaration of Helsinki. Medisch Ethische Toetsingscommissie (METc) of VU University has approved the procedures for brain tissue collection, and the regional ethical review board in Lund has approved the study. All human data were analyzed anonymously.

\section{Antibodies}

Antibodies used for this study: anti-rabbit iNOS primary antibody (1:5000, Santa Cruz), anti-rat gal3 antibody (1:3000, M38 clone from Hakon Leffler's lab, in-house antibody), anti-goat gal3 antibody (1:1000, R\&D Systems), antimouse actin antibody 1:10,000 (Sigma-Aldrich), anti-human $\mathrm{A} \beta$ antibody (1:5000, Covance), anti-rabbit Iba-1 antibody (1:500, Wako), anti-mouse TLR4 antibody (1:1000, Santa Cruz), anti-mouse NLRP3 antibody (1:5000, Adipogen), anti-rabbit C83 antibody (369) (1:1000, Gunnar Gouras Laboratory, BMC, Lund, Sweden), TREM2 antibody 1:500 (AF1729, anti-sheep) anti-rabbit IDE-1 antibody (1:1000, Calbiochem), anti-Rabbit p-Tau (pTau181, 1:1000, Santa Cruz), anti-mouse $A \beta$ (1:1000, Sigma-Aldrich), anti-CD45 rat monoclonal (clone IBL-3/16, 1:500, AbD Serotec), anti-CD68 (1:500, eBiosciences) and anti-Clec7a rabbit monoclonal (1:500, abcam). Secondary antibodies used for western blot were anti-rabbit, anti-mouse, anti-goat and anti-rat from Vector Labs. Secondary antibodies used for immunofluorescence were raised in donkey and were antirabbit, anti-goat, anti-mouse and anti-rat from Life Technology (AlexaFluor).

\section{Inhibitor used in our study}

The inhibitor used for the experiments in suppl. Fig. 5 (online resource 5) was 1,1'-sulfanediyl-bis-3-deoxy-3-4-3fluorophenyl-1 $H$-1,2,3-triazol-1-yl- $\beta$-D-galactopyranoside [45] (inhibitor 1). It was synthesized and characterized as reported previously [16]. The purity was determined to be 97.3\%, according to UPLC-analysis (Waters Acquity UPLC system, column Waters Acquity CSH C18, $0.5 \mathrm{ml} / \mathrm{min}$ $\mathrm{H}_{2} \mathrm{O}-\mathrm{MeCN}$ gradient 5-95\% 10 min with $0.1 \%$ formic acid). 


\section{Results}

\section{Galectin-3 is expressed in microglial cells positioned next to amyloid plaques in AD human cortical samples and 5XFAD mice}

We first evaluated the levels of gal3 in cortical sections from AD patients and age-matched healthy controls (Fig. 1a). We found a ten-fold increase of gal3 in AD patients compared to controls. Next, we stained for gal3, A $\beta$ and microglia (Iba1) in AD and healthy cortical sections (Fig. 1b, c). The expression of gal3 was mostly absent in the control samples with a faint staining in brain blood vessels (Fig. 1c). However, in the AD cortical samples, there was robust gal3 staining in Iba ${ }^{+}$cells (Fig. 1c), which was strictly confined to $A \beta$ plaque-associated microglia (Fig. 1b). To further confirm our observations, we used 5xFAD mice, a transgenic AD mouse model, and found the expression of gal 3 significantly upregulated in a time-dependent fashion from 6 to 18 months (Fig. 1d; suppl. Fig. 1, online resource 1). In 5xFAD brains, gal3 was typically found in microglial cells associated with $A \beta$ plaques (Fig. 1e). No noticeable gal3-expressing microglia was found neither in hippocampus nor in cortex in 18-month-old WT mice (data not shown).

We also analyzed two early stages of 5xFAD mice, including 6 weeks (no sign of plaque is detected at this age)
Fig. 1 Galectin-3 is increased in human and mouse $\mathrm{AD}$ brains and marks a microglial phenotype associated with $\mathrm{A} \beta$ plaques. a Western blot analyses of cortex from human $\mathrm{AD}$ cases $(n=6)$ and age-matched healthy controls $(n=5)$. b Galectin-3 (gal3) staining mainly coincided with $\mathrm{Iba}^{+}$ microglia found around $\mathrm{A} \beta$ plaques in human $\mathrm{AD}$ brains. $\mathbf{c}$ Immunohistochemistry showed high levels of gal3 in microglia in $\mathrm{AD}$ brains, as compared to Iba1-staining (low levels of gal3 was detected in association to blood vessels). d Gal3 protein was significantly upregulated in the cortex of $5 \mathrm{xFAD}$ mice in a time-dependent fashion (WT, 6 months old). e Gal3 expression was found in $\mathrm{Iba}^{+}$cells around $\mathrm{A} \beta$ plaques. Statistical significance was calculated by one-way ANOVA with Tukey's correction (d) or Student's $t$ test (a). ${ }^{*} p<0.05$; $* *<<0.01$. Data are shown as mean \pm SD. The human $\mathrm{AD}$ cases are described in suppl. Tables S1 and S2 (online resources 8 and 9)

\section{a}

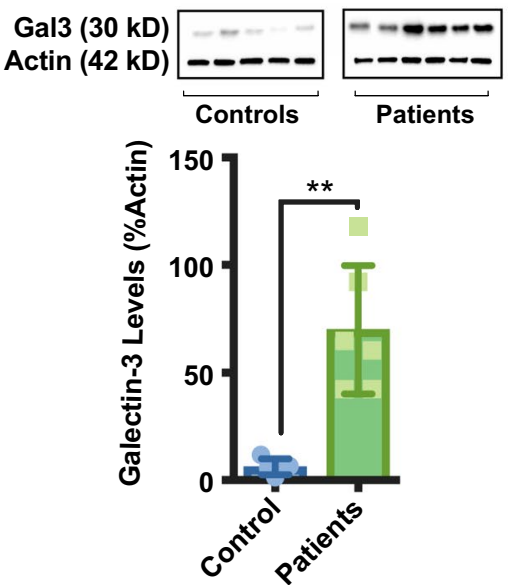

Human

b

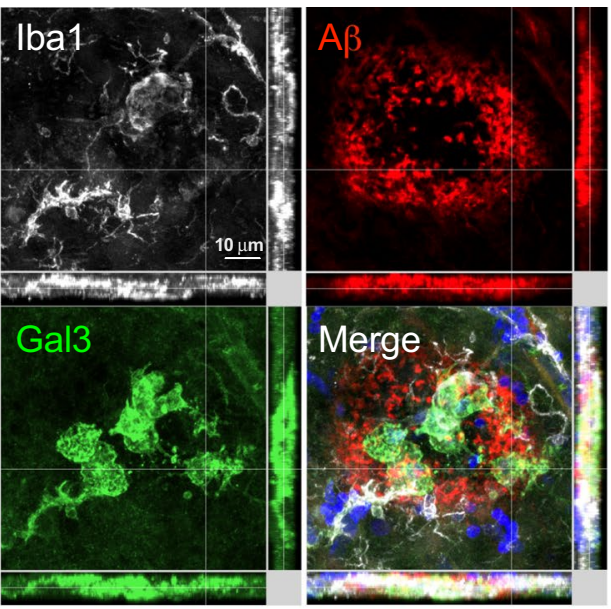

C

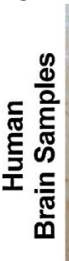

Control
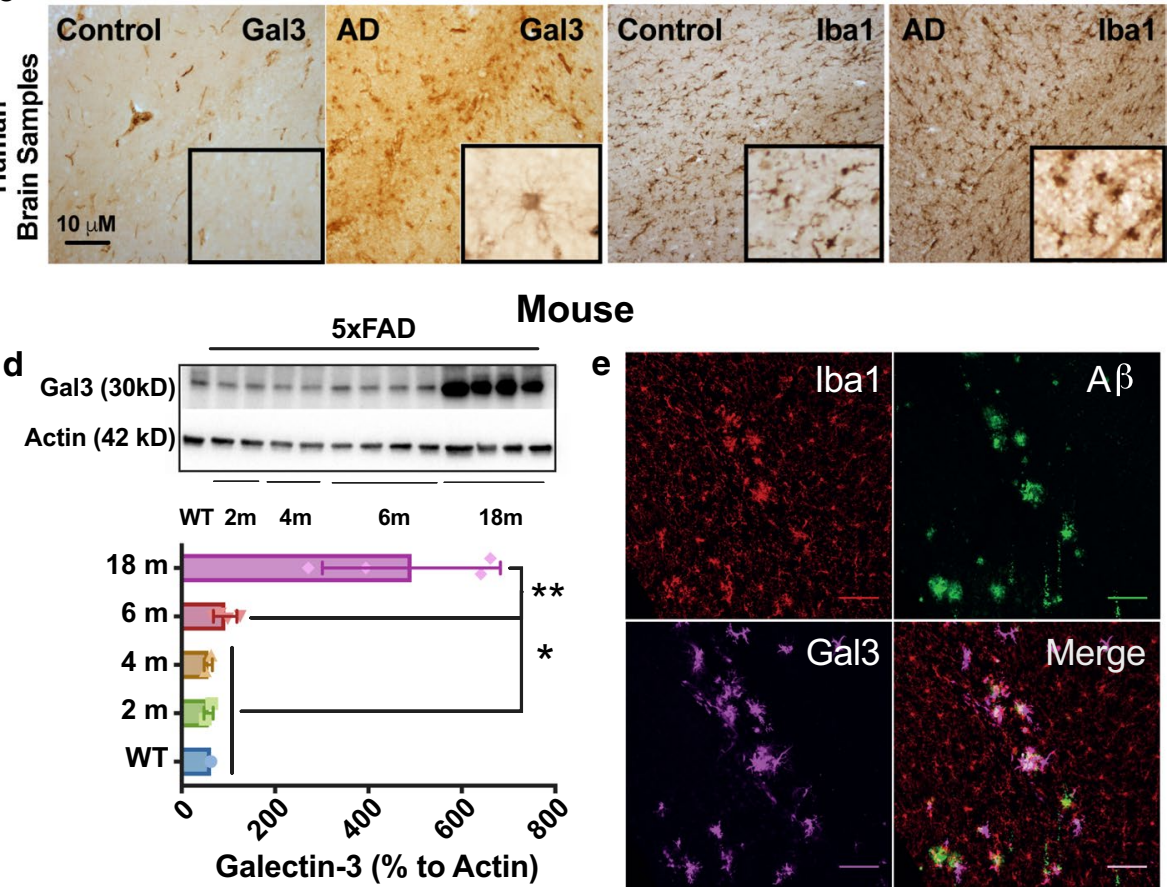
and 10 weeks (first early plaques appear in the subiculum) (suppl. Fig. 1b, c, online resource 1). This temporal analysis demonstrated the appearance of gal3-expressing microglia at very early stages of the disease, before pre-plaque formation. At 6 weeks, it was evident that the gal3-expressing microglial cells were located close to APP expressing neurons even with no sign of $A \beta$ plaque deposition (suppl. Fig. 1, online resource 1). Despite this close association, further experiments are required to decipher its biological significance. We also investigated if other cell types in 5xFAD mice expressed gal3 by looking at GFAP-labeled astrocytes and NeuN-labeled neurons. This study demonstrated that plaque-associated microglia is the predominant cell type expressing gal3. Yet, $13 \%$ of reactive astrocytes expressed gal3 in 6-month-old 5xFAD mice. That figure dropped to less than $2 \%$ in 18 -month-old 5xFAD mice (suppl. Fig. 2, online resource 2). On the other hand, neurons expressing gal3 were rarely observed even after analyzing several hippocampal sections. The expression of neuronal gal 3 was, therefore, considered very exceptional (suppl. Fig. 2c, online resource 2).

\section{Single-nucleotide polymorphisms (SNP) associated with the gal3 gene increase the risk of developing AD}

We performed genetic association studies using a SNP metaanalysis approach of the $L G A L S 3$ gene, which encodes gal3. A total of 60 SNPs was identified in the LGALS3 genetic region. Only five SNPs were genotyped in at least three GWAS (suppl. Fig. 3a, suppl. Table 3, online resource 3 and 10) and were found to be in high linkage disequilibrium ( $d^{\prime}>0.96$; suppl. Fig. 3b, online resource 3). Interestingly, all five SNPs were associated with an increased AD frequency ( $p<0.03$; suppl. Table 3, online resource 10), suggesting a potential causal role of gal 3 in the development of $\mathrm{AD}$.

\section{Galectin-3 regulates amyloid-dependent microglial activation}

To investigate the role of gal3 in microglial activation in $\mathrm{AD}$, we first evaluated the inflammatory response in BV2 microglial cells. fA $\beta$ was characterized prior to the experiments (suppl. Fig. 5a, online resource 5). Our preparation was tested for LPS endotoxin as well as for cell toxicity (suppl. Fig. 5b, c, online resource 5). BV2 cells challenged with $\mathrm{fA} \beta$-activated microglial cells, inducing the expression of iNOS and NLRP3 (suppl. Fig. 5d, online resource 5) and the production and release of proinflammatory cytokines (suppl. Fig. 5e, online resource 5). Next, we challenged BV2 cells with $10 \mu \mathrm{M} \mathrm{fA} \beta$ along with increasing concentrations of gal3 inhibitor (10 and $25 \mu \mathrm{M})$ for $12 \mathrm{~h}$. The conditioned media was collected, and inflammatory-related cytokines were measured. Notably, the release of proinflammatory cytokines TNF $\alpha$, IL12 and IL8 was significantly reduced in response to gal3 inhibition in a concentration-dependent manner (suppl. Fig. 5f, online resource 5). The same was true for iNOS, a classical proinflammatory marker as measured by western blot (suppl. Fig. 5g, online resource 5). We also evaluated the levels of insulin degrading enzyme 1 (IDE-1) in BV2 cells. IDE-1 is an enzyme involved in $\mathrm{A} \beta$ degradation [48]. IDE-1 was downregulated in BV2 cells challenged with fA $\beta$ in a concentration-dependent fashion (suppl. Fig. 5i, left, online resource 5). Strikingly, with gal3 inhibition, the downregulation of $A \beta$-induced IDE-1 turned into a significant upregulation in a manner dependent on inhibitor concentration (suppl. Fig. 5i, online resource 5). To confirm our in vitro data, we evaluated the inflammatory response using primary microglial cultures from WT and Gal3KO mice. Primary microglial cultures were challenged with $\mathrm{fA} \beta$ at 3 and $10 \mu \mathrm{M}$. Similar to BV2 cells, the lack of gal3 reduced the release of proinflammatory cytokines, such as IL6, IL8 and TNF $\alpha$ (Fig. 2a). Other cytokines, such as IFN $\gamma$, IL4 and IL12, were not affected by the lack of gal3. We next analyzed the effect of gal3 on the phagocytosis of either $A \beta$ monomers $(\mathrm{mA} \beta)$ or $A \beta$ fibrils (fA $\beta$ ) by primary microglia. To achieve this, primary microglial cells were either pretreated (30 min) or simultaneously with gal3 $(1 \mu \mathrm{M})$ upon challenge with $\mathrm{mA} \beta$ or $\mathrm{fA} \beta$. Microglial uptake of $A \beta$ was increased when $\mathrm{mA} \beta$ and gal 3 were added simultaneously (suppl. Fig. 2e, online resource 2). Interestingly, when using pretreatment of fA $\beta$ (suppl. Fig. 2f, online resource 2), we found a reduced microglial uptake, suggesting a perplex role of gal 3 in $\mathrm{A} \beta$ phagocytosis. We have previously demonstrated the ability of gal3 to be released by proinflammatory microglia in response to TLR activation, which was shown to be a determinant feature in driving microglia-related immune responses [9, 64]. Given the strong response to either gal3 deletion or gal3 inhibition in the prevention of the $f A \beta$-induced microglia proinflammatory activation, we next analyzed if cultured microglia challenged with $\mathrm{fA} \beta$ actively release gal3. Gal3 levels were analyzed in conditioned media using ELISA. This analysis demonstrated a prominent release of gal 3 in response to $\mathrm{fA} \beta$ in both primary microglia cultures and BV2 cells (Fig. 2b and suppl. Fig. 5h, online resource 5).

\section{Galectin-3 regulates microglial activation in 5xFAD mice}

To examine the role of gal3 in the neuroinflammatory response, WT, 5xFAD mice and crossbred 5xFAD/Gal3KO mice were compared. Transcriptional profiles of hippocampal tissue were obtained by running high-throughput qPCR against a 632-gene mouse inflammation panel. WT and 


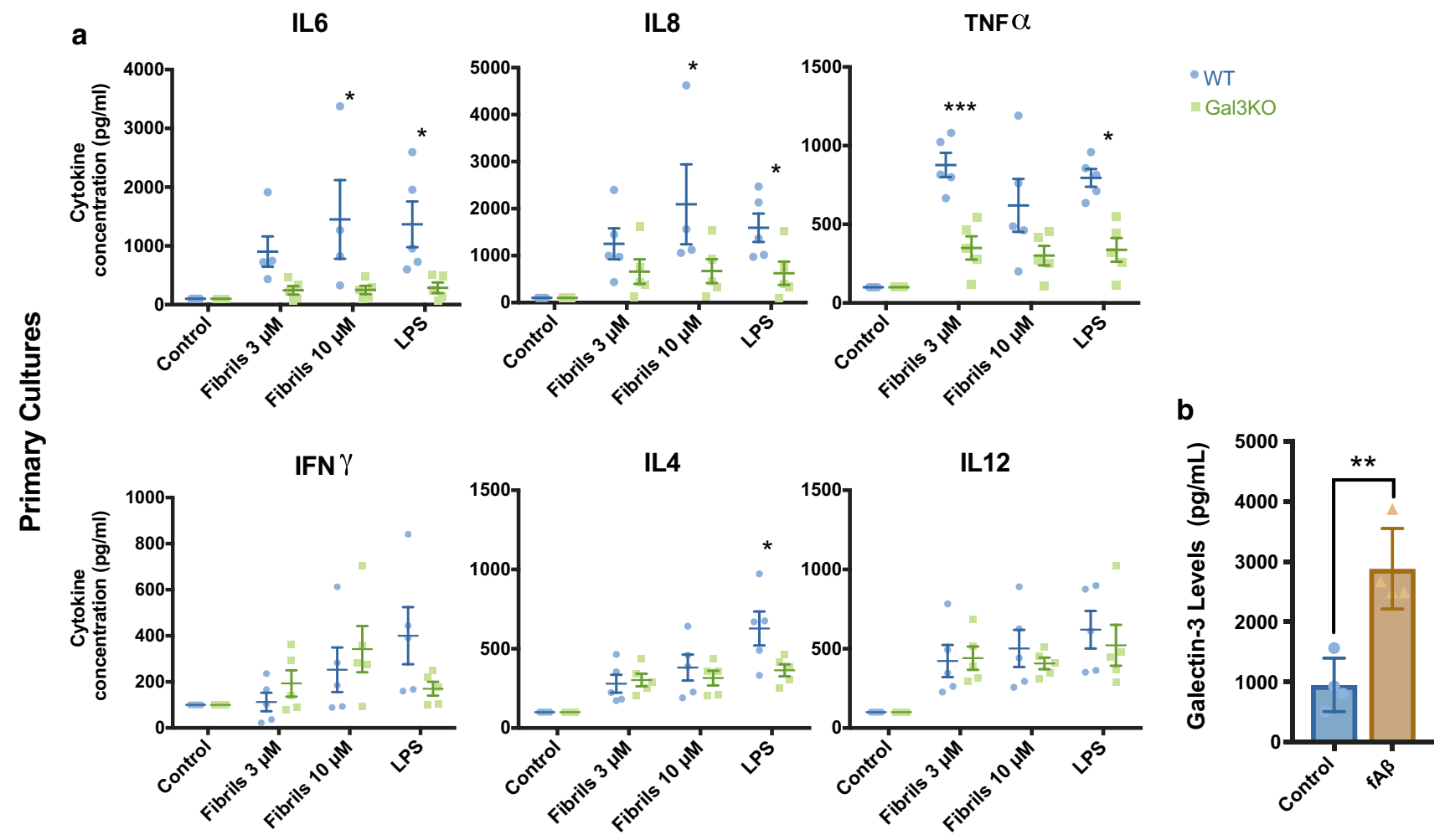

Fig. 2 Galectin-3 deficiency/inhibition reduces the microglial inflammatory response in vitro. a Reduced cytokine levels in culture medium from Gal3KO primary microglial cultures compared to WT after fA $\beta$ treatment for $12 \mathrm{~h}$. b WT primary microglial cultures increase the release of gal 3 upon stimulation with $\mathrm{fA} \beta$. In vitro

Gal3KO mice showed quite similar profiles, suggesting a limited role of gal 3 in promoting inflammation in the absence of pathology. In 5xFAD mice, compared to WT, a significant number of genes were affected, especially in 18-month-old mice, in which 125 out of 629 immune genes were highly upregulated, including: complement factors, chemokines, interleukin receptors and toll-like receptors (suppl. Fig. 4, online resource 4). Overall, the whole immune response was highly attenuated in 5xFAD/Gal3KO mice (suppl. Fig. 4, online resource 4). Interestingly, genes associated with the recently characterized neurodegenerative disease-associated phenotype (DAM microglia [27, 30]), such as Clec7a, Csf1, Cd74, Cxcl10 and Cybb (Fig. 3a, b, d), were downregulated in $5 \mathrm{xFAD} / \mathrm{Gal} 3 \mathrm{KO}$ mice compared to $5 \mathrm{xFAD}$ mice. $\mathrm{qPCR}$ analysis of homeostatic (Cx3cr1, TGF $\beta 1)$ and DAM/reactive microglia (CD45, TREM2, Clec7a, CD68, TNF $\alpha$ and Lysozyme M) confirmed the instrumental role of gal3 in driving the brain immune response in 5xFAD mice (Fig. 3). To identify potential cell signaling pathways related to gal3 in 5xFAD mice, we used NetworkAnalyst (http://www.netwo rkanalyst.ca) [61]. Most affected pathways were related to TLR receptors and DAP12 signaling (Fig. 3b, d). DAP12 has been described as a TREM2 adaptor and plays a critical experiments represent a minimum of three independent experiments. Statistical significance was calculated by Student's t-test (b), or oneway ANOVA with Tukey's correction (a) $*_{p}^{*}<0.05 ; * * p<0.01$; $* * * p<0.001$. Data are shown as mean $\pm \mathrm{SD}$

role in the switch from homeostatic to disease-associated microglian [27, 30]. Our data anticipate a key role of gal3 in driving microglial activation in $\mathrm{AD}$ through regulation of different microglial pattern-recognition receptors, including TLRs and TREM2.

\section{The lack of galectin-3 reduces AD pathology in 5XFAD mice}

Once we confirmed the important role of gal3 in driving AD-associated microglial immune responses, we next analyzed the effect of gal3 in $\mathrm{AD}$ pathogenesis. There was clear age-dependent $\mathrm{A} \beta$ deposition in 5xFAD mice (Fig. 4). A $\beta$ deposition in aged animals (18 months) was higher; an indication that $\mathrm{A} \beta$ clearance becomes saturated in aged $5 \mathrm{xFAD}$ mice. Consequently, to detect a potential effect of gal 3 in $A \beta$ burden, we analyzed the effect of gal 3 gene deletion in two well-defined areas, the hippocampal CA1 area (high rate of $\mathrm{A} \beta$ deposition) and the thalamus (low rate of $\mathrm{A} \beta$ deposition), in 5xFAD mice at 6 and 18 months of age. Notably, the plaque burden was significantly reduced in $5 \times \mathrm{FAD}$ mice lacking gal 3 at 6 months in the CA1 region (Fig. 4a). At 18 months, we could not find any difference between the 
a \begin{tabular}{|cc}
0 & -5 \\
\hline &
\end{tabular} Log 2FC 5xFAD/Gal3KO vs 5xFAD (18 months)

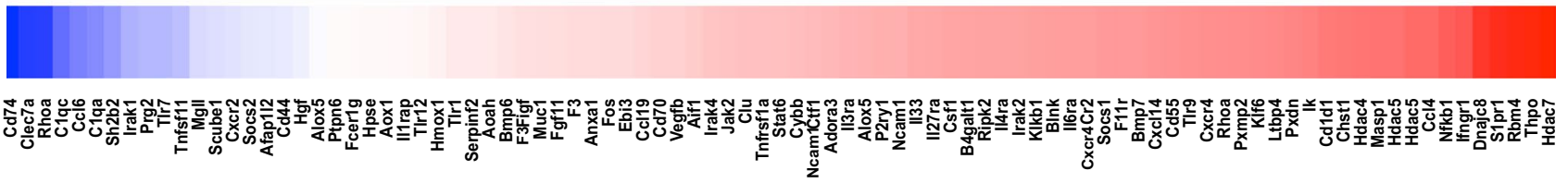

b


C

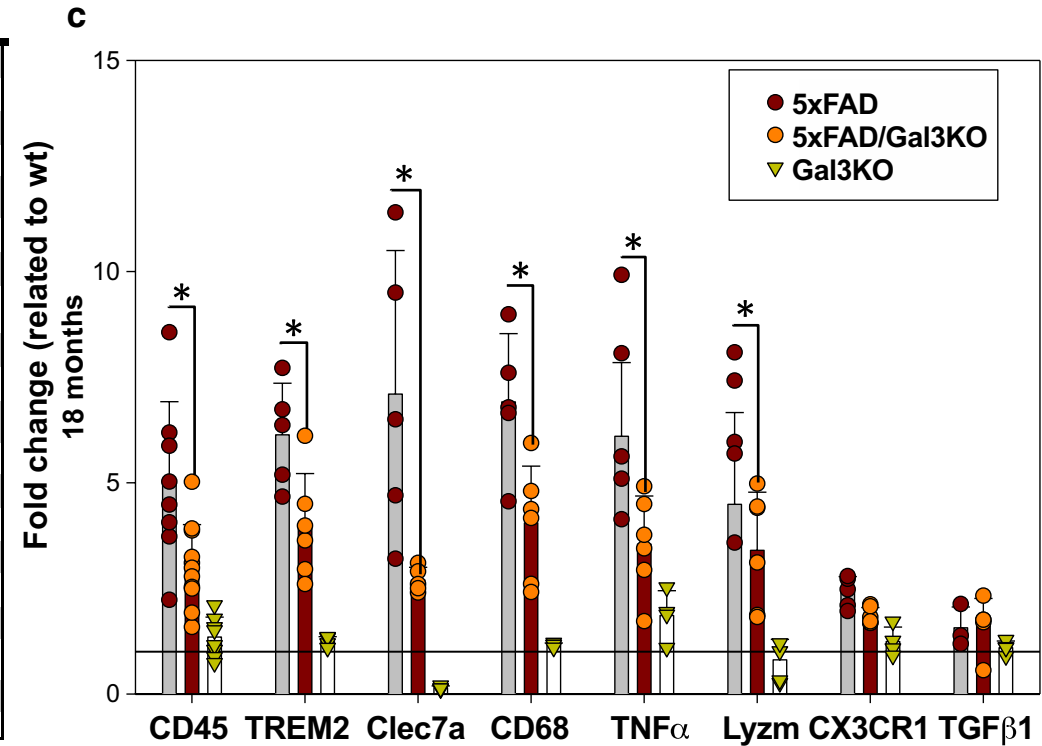

CD45 TREM2 Clec7a CD68 TNF $\alpha$ Lyzm CX3CR1 TGF $\beta 1$

d

\begin{tabular}{|cc|}
\hline Hits & p-Value \\
\hline 79 & $1,56 \mathrm{e}-70$ \\
43 & $2,82 \mathrm{e}-51$ \\
37 & $1,17 \mathrm{e}-44$ \\
38 & $3,34 \mathrm{e}-34$ \\
35 & $2,96 \mathrm{e}-42$ \\
35 & $2,96 \mathrm{e}-42$ \\
35 & $2,96 \mathrm{e}-42$ \\
33 & $2,42 \mathrm{e}-41$ \\
33 & $4,01 \mathrm{e}-41$ \\
33 & $4,01 \mathrm{e}-41$ \\
47 & $2,38 \mathrm{e}-40$ \\
38 & $1,02 \mathrm{e}-36$ \\
30 & $2,34 \mathrm{e}-36$ \\
30 & $2,34 \mathrm{e}-36$ \\
38 & $1,12 \mathrm{e}-35$ \\
45 & $1,98 \mathrm{e}-35$ \\
29 & $3,4 \mathrm{e}-35$ \\
29 & $3,4 \mathrm{e}-35$ \\
29 & $3,4 \mathrm{e}-35$ \\
29 & $3,4 \mathrm{e}-35$ \\
\hline &
\end{tabular}

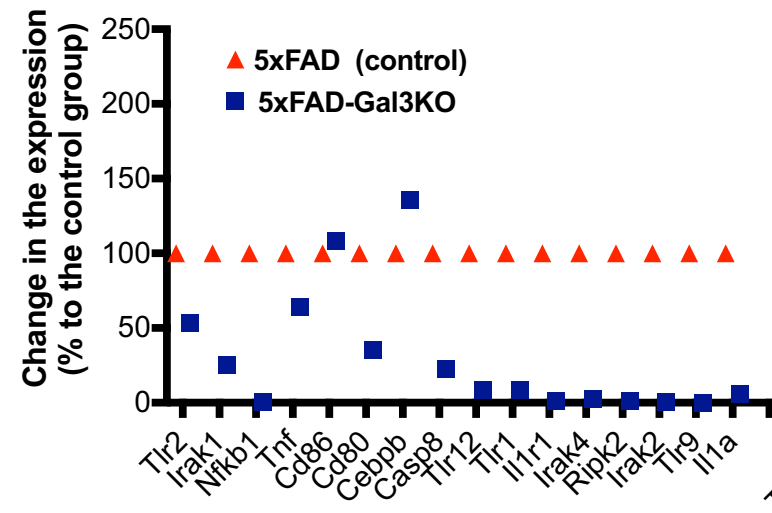

TLR associated genes

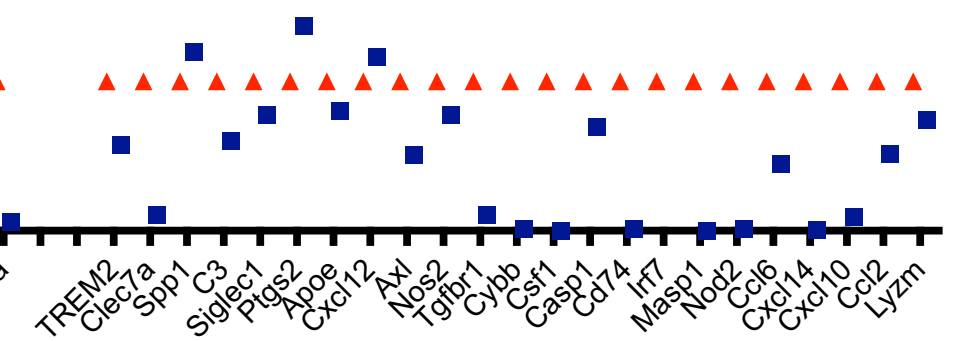

DAM genes
Fig. 3 Galectin-3 reduces the microglial inflammatory response in vivo mainly through TLR and DAP12 pathways. a Heat map of the 100 most upregulated inflammatory genes in 18-month-old 5xFAD mice vs. WT and how these genes are altered in $5 \mathrm{xFAD} / \mathrm{Gal} 3 \mathrm{KO}$ mice. Data expressed in $\log 2 \mathrm{FC}$. b Inflammatory pathways affected in hippocampi of 5xFAD/Gal3KO mice compared to 5xFAD mice. $\mathbf{c}$ Expression of homeostatic and proinflammatory microglial genes in

groups, possibly due to oversaturated plaque deposits in the hippocampi (Fig. 4b). In agreement with this view, a significant reduction in $\mathrm{A} \beta$ plaque deposition was found in the thalamus in $5 \mathrm{xFAD} / \mathrm{Gal} 3 \mathrm{KO}$ mice at 6 and 18 months
5xFAD and 5xFAD/Gal3KO using qPCR in aged mice (18 months). d Main TLR-associated genes and disease-associated microglia (DAM) genes affected in aged mice (18 months); red triangle is $5 \mathrm{xFAD}$ reference gene expression and blue square is $5 \mathrm{xFAD} / \mathrm{Gal} 3 \mathrm{KO}$ gene expression. Data are expressed in folds $\Delta \mathrm{CT}$. Statistical significance was calculated by one-way ANOVA with Tukey's correction. $* p<0.05$. Data are shown as mean \pm SD

compared to aged-matched 5xFAD controls (Fig. 4a, b). We also performed an analysis of amyloid plaque morphology (size, circularity and perimeter). We compared thioflavinS-positive plaques in $5 \mathrm{xFAD} / \mathrm{Gal} 3 \mathrm{KO}$ and $5 \mathrm{xFAD}$ mice at 

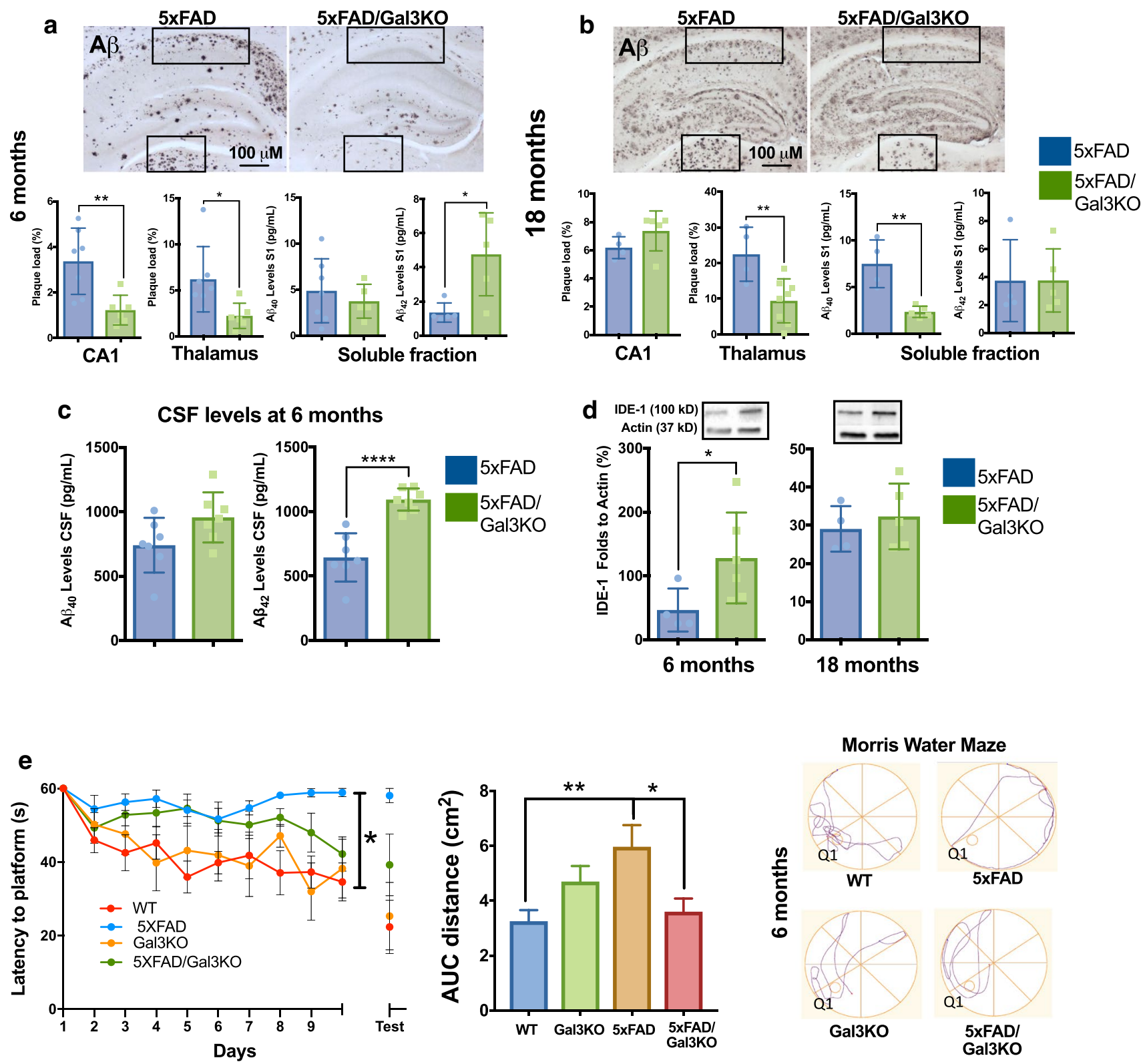

Fig. 4 Lack of galectin-3 reduces $\mathrm{AD}$ pathology in $5 \mathrm{xFAD}$ mice. $\mathrm{A} \beta$ load in hippocampus (CA1) and thalamus at 6 months (a) and 18 months (b) with A $\beta$ load analyzed in 5xFAD and 5xFAD/Gal3KO mice (\% in frames). Soluble fractions of $A \beta 40$ and $A \beta 42$ levels in cortical S1 fraction were measured (pg/ml). c A $\beta 40$ and $A \beta 42$ levels in CSF samples at 6 months (pg/mL). d IDE-1 levels in 5xFAD and 5xFAD/Gal3KO mice at 6 and 18 months. e Spatial memory ana-

6 and 18 months. This analysis first demonstrated that aged animals exhibited a near threefold increase in plaque area in both experimental groups when compared to 6-monthold animals. Notably, at 18 months, we found a significant reduction in plaque perimeter and circularity in 5xFAD/ Gal3KO mice compared to 5xFAD mice (suppl. Fig. 6c, online resource 6 ). Next, we measured cortical $A \beta 42$ and lyzed by Morris water maze test. Center, distance traveled (meters) as an integrated distance ( $A U C$ area under the curve). Left, latency to the platform during training trials. Right, representative runs of probe trial day. Q1, quadrant where the platform was located on training trial. Statistical significance was calculated by two-way (with Bonferroni's post hoc) (e) and Student's t-test $(\mathbf{a}-\mathbf{e}) . * p<0.05 ; * * p<0.01$; $* * * p<0.001 ; * * * * p<0.0001$. Data are shown as mean \pm SEM

A $\beta 40$ levels in soluble brain fractions. The levels of $A \beta 40$ were significantly lower in 5xFAD/Gal3KO (vs. 5xFAD) brains at 18 months but not at 6 months (Fig. 4a, b). Conversely, A $\beta 42$ levels were significantly higher in 5xFAD/ Gal3KO (vs. 5xFAD) brains at 6 months (Fig. 4a) but with no change at 18 months (Fig. 4b). In the insoluble $A \beta$ fraction, we found reduced $\mathrm{A} \beta 40$ levels in $5 \mathrm{xFAD} / \mathrm{Gal} 3 \mathrm{KO}$ mice 
at 6 months (suppl. Fig. 6a, online resource 6). Changes in A $\beta 40$ and $A \beta 42$ levels were not due to a change of APP expression as 5xFAD and 5xFAD/Gal3KO mice showed comparable levels at both ages measured (suppl. Fig. 6b, online resource 6 ). $A \beta$ is cleared from the brain by different mechanisms, including microglia phagocytosis, drainage to the ventricular system and activity of extracellular proteases, such as IDE-1 [18]. We found a significant increase of A 342 CSF levels in 5xFAD/Gal3KO mice compared to $5 x F A D$ mice (Fig. 4c), mimicking the clinical situation in which $A \beta$ in the CSF is inversely related to the $A \beta$ plaque load in AD patients. Interestingly, hippocampal IDE-1 levels were increased in $5 \mathrm{xFAD} / \mathrm{Gal} 3 \mathrm{KO}$ mice at 6 months compared to $5 \mathrm{xFAD}$ mice (Fig. $4 \mathrm{~d}$ ), confirming our in vitro data (suppl. Fig. 5i, online resource 5). Since phagocytosis is also involved in $\mathrm{A} \beta$ clearance, we analyzed CD68-labeled phagosome areas that have been shown to correlate with in vivo $\mathrm{A} \beta$ phagocytosis [65] at 6 months and 18 months in $5 \mathrm{xFAD}$ and $5 \mathrm{xFAD} / \mathrm{Gal} 3 \mathrm{KO}$ mice. No significant differences were found between both experimental groups at any of the ages examined (suppl. Fig. 6d, online resource 6).

Taken together, our data are suggestive of an important negative role of gal 3 in $A \beta$ clearance in $5 x F A D$ mice. This view is sustained by the higher CSF levels of $A \beta 42$ and increased expression of extracellular IDE-1 in 5xFAD/Gal3 KO mice when compared to 5xFAD mice (Fig. 4).

Having established that gal3 is a main driver of the ADassociated inflammatory response and that gal3 deficiency reduces $A \beta$ plaque burden, we next studied the impact of gal3 deficiency on cognitive behavior. The cognitive ability was evaluated using the Morris water maze memory test. Remarkably, the lack of gal3 in 5xFAD/Gal3KO mice resulted in better cognitive performance compared to $5 \mathrm{xFAD}$ mice as the $5 \mathrm{xFAD} / \mathrm{Gal} 3 \mathrm{KO}$ mice were able to navigate and reach the platform using a shorter path (Fig. 4e).

\section{Galectin-3 drives microglia reactivity in $\mathrm{A} \beta$ plaques}

In light of our findings that gal3-reactive microglia are strictly confined to $\mathrm{A} \beta$ plaques and that gal 3 deficiency impairs the inflammatory response and $\mathrm{A} \beta$ plaque load, we next analyzed microglial coverage on the surface of amyloid plaques in cortex from both $5 \mathrm{xFAD}$ and $5 \mathrm{xFAD} / \mathrm{Gal} 3 \mathrm{KO}$ mice at 18 months of age. First, we found that 5xFAD/ Gal3KO mice showed reduced Iba1 immunoreactivity in the cortex when compared to 5xFAD mice (Fig. 5a). These differences were particularly evident in plaque-associated microglia in 5xFAD/Gal3KO mice (Fig. 5b). Remarkably, gal3 deficiency significantly reduced Iba1-labeled microglial clusters around $A \beta$ plaques (Fig. $5 \mathrm{c}$ ). Still, an analysis of microglial coverage over plaque surfaces showed that a high subset of plaque-associated microglia $(\sim 50 \%)$ expressed high levels of gal3 (Fig. 5d). Interestingly, these findings are, to some extent, similar to the findings seen in studies of 5xFAD/TREM2KO mice [39, 59, 65], yet, substantial differences are evident between 5xFAD lacking either gal3 or TREM2. Thus, contrary to that seen in 5xFAD lacking gal3, $5 \times \mathrm{FAD} / \mathrm{TREM} 2 \mathrm{KO}$ mice exhibits increased $\mathrm{A} \beta$ deposition in the hippocampal formation [59]. Further, microglia lacking TREM2 fail to colocalize in $A \beta$ plaques [59], an ability present in microglia lacking gal3. Taken together, our data suggest that gal3-associated biological effects may be associated with TREM2 signaling without excluding other significant biological pathways (i.e., TLR signaling).

\section{Galectin-3 acts as a TREM2 ligand}

Recent single-cell transcriptomic analyses of microglia under different conditions of neurodegeneration, including $\mathrm{AD}$, have revealed that gal3 is one of the most upregulated genes in processes that have been suggested to be TREM2-dependent $[30,38]$. We have demonstrated that gal3 is released by reactive microglial cells [9] and may thus interact with different receptors controlling key functions of microglial cells, including TLR4 [38] and MerTK [43]. One of the main pathways altered in 5xFAD/Gal3KO mice was related to DAP12 signaling (Fig. 3b). Since DAP12 is a downstream regulator of TREM2, we wondered if gal3 could act as an endogenous TREM2 ligand. To test our hypothesis, we first performed TREM2, gal3 and 6E10 staining on $5 \mathrm{xFAD}$ brain sections and found that the majority of TREM2-labeled microglia were gal3 ${ }^{+}(83.4 \pm 5.7 \%$ and $94.0 \pm 3.02 \%$ at 6 and 18 months, respectively), an indication that gal3 immunoreactivity may label the DAM phenotype $[27,30]$ (Fig. 5e, suppl. Fig. 7a, online resource 7). To further support this view, we performed Clec7a immunostaining on 5xFAD brain sections. Clec7a has been identified as a specific microglial marker associated with both the DAM phenotype [27] and the microglial neurodegenerative phenotype [30]. Our confocal analysis demonstrated that plaque-associated microglia express the markers Clec7a and gal3 (suppl. Fig. 2d, online resource 2), thus supporting the view that DAM express gal3. Our analysis also demonstrated a striking cellular colocalization of TREM2 and gal 3 in microglial cells around $A \beta$ plaques (Fig. 5e, f, suppl. Fig. 7a, online resource 7). Despite the clear relation between TREM 2 and gal 3 in microglial cells-associated amyloid plaques, further experiments (such as single-cell analysis) are required to fully elucidate how gal3 is related to DAM microglia.

We next used quantitative high-resolution confocal microscopy and super-resolution stochastic optical reconstruction microscopy (STORM) to determine whether TREM2 and gal3 physically interact in brain sections from $5 x F A D$ mice. Our ultrastructural analysis clearly revealed the physical interaction between gal3 (green) and TREM2 

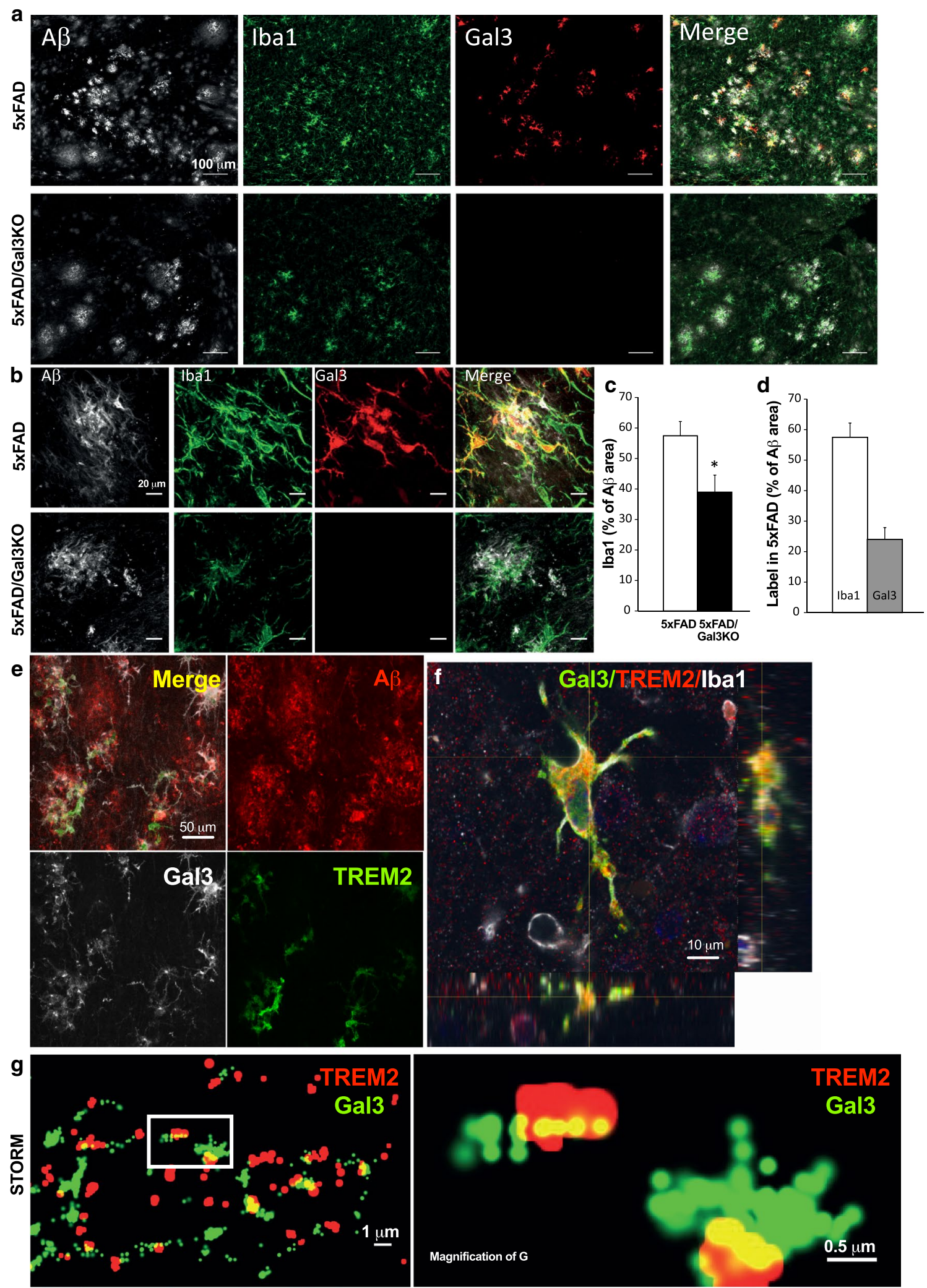

(red) over the membrane surface of microglia (see yellow dots in Fig. 5g). Further, we incubated brain sections from $5 x F A D / G a l 3 K O$ mice with recombinant gal3 to further analyze gal 3 binding in situ. This experiment demonstrated the binding of gal 3 to TREM $2^{+}$but not to TREM2-/Iba $1^{+}$ microglial cells (suppl. Fig. 7b, online resource 7). 
4Fig. 5 Galectin-3 colocalizes with TREM2. a, b Iba1 ${ }^{+}$cells expressing galectin-3 (gal3) around $\mathrm{A} \beta$ plaque in $5 \mathrm{xFAD}$ mice. $\mathbf{c}$ Reduced number of $\mathrm{Iba1}^{+}$microglial cells around $\mathrm{A} \beta$ plaques in $5 \mathrm{xFAD} /$ Gal3KO mice compared to 5xFAD mice (\% of $A \beta$ area). $\mathbf{d}$ Number of $\mathrm{Iba}^{+}$cells expressing gal 3 in $5 \mathrm{xFAD}$ ( $\%$ of $\mathrm{A} \beta$ area). e, $\mathbf{f ~ G a l} 3$ and TREM2 in plaque-associated microglia in the brain of $5 x F A D$ mice reveals colocalization of gal 3 and TREM2. g Gal3 and TREM2 colocalization in 5xFAD mouse brain using STORM microscopy. Statistical significance was calculated by Student's $t$ test. $* p<0.05$. Data are shown as mean \pm SEM. All images were taken in $5 \times$ FAD mice at 18 months

We further assessed the direct TREM2-gal3 interaction by determining the ability of soluble TREM 2 to inhibit the binding of a fluorescent glycosylated probe to gal 3 as measured by fluorescence anisotropy (Fig. 6a). This analysis demonstrated a strong interaction between WT gal3 and TREM2 with a $K_{\mathrm{d}}$ value of $450 \pm 90 \mathrm{nM}$ (Fig. 6a), which was in the same range as other preferred glycoproteins [11, 12]. A mutant gal3 (R186S, deficient in the carbohydrate-binding domain with severely reduced affinity for LacNAc-structures) [49], in comparison, weakly bound to TREM2 $\left(K_{\mathrm{d}}\right.$ of $5900 \pm 600 \mathrm{nM}$; Fig. 6a). This means that gal3 interacts strongly with TREM2, with a $K_{\mathrm{d}}$ in the same range as, for example, some serum glycoproteins such as transferrin and haptoglobin $[11,12]$. The data also suggest that the interaction between gal3 and TREM2 is carbohydrate dependent. The hypothesized interaction was modeled based on previously reported TREM2 and gal3 structures (suppl. Fig. 7c, online resource 7). Next, we tested whether gal 3 could affect TREM2 signaling using a TREM2-DAP12 reporter cell line, and we found that added gal3 triggered TREM2-DAP12dependent signaling in a dose-dependent manner (Fig. 6b). Overall, our data demonstrate that gal3 is an endogenous ligand for TREM2.

\section{Galectin-3 induces the formation of insoluble $A \beta$ aggregates following injections of $A \beta$ in the hippocampi of WT mice}

We have previously demonstrated that gal3 can be released by reactive microglial cells in vitro and in vivo [9]. In this study we provide convincing evidence that primary microglia and BV2 cells actively release gal3 when challenged with $\mathrm{fA} \beta$ and that gal 3 may act as an endogenous TREM 2 agonist. Intriguingly, TREM 2 has been associated with $A \beta$ plaque compaction [65], and, hence, the possibility emerged that gal 3 may have a role in $A \beta$ aggregation. To address this, $A \beta 42$ monomers $(10 \mu \mathrm{M})$ were incubated alone or in the presence of gal $3(10 \mu \mathrm{M})$ for $1 \mathrm{~h}$ at $37^{\circ} \mathrm{C}$ (suppl. Fig. $6 \mathrm{f}$, online resource 6 ). A ThT assay was performed under the same conditions and demonstrated that $\mathrm{fA} \beta$, which reached the maximal ThT fluorescence intensity, was the predominant form of $A \beta$ aggregates used for the in vivo injections (suppl. Fig. 6f, online resource 6). Two microliter of the prepared $A \beta$ was injected in either the left $(A \beta+$ gal3) or the right hippocampi (A $\beta$ alone) of WT mice. The analysis was performed 2 months post-injection. The injection of $A \beta$ alone failed to induce $A \beta$ aggregation in the injected hippocampi (Fig. 7a). In sharp contrast and remarkably, A $\beta$-like plaques were evident in the hippocampi injected with $A \beta+$ gal 3 (Fig. 7b, c). These $A \beta$ aggregates were positive for gal3, $\mathrm{A} \beta$ (detected with $6 \mathrm{E} 10$ antibody) and thioflavin-S (Fig. 7d, e), which demonstrate the amyloid structure of the $A \beta$ deposits. These amyloid deposits were surrounded by $\mathrm{Iba}^{+}{ }^{+}$-labeled microglia (Fig. $7 \mathrm{f}$ ) and $\mathrm{GFAP}^{+}$reactive astrocytes (Fig. 7g). Animals injected with $A \beta$ alone did not present aggregate deposits or microglial/astrocyte activation (suppl. Fig. 6e, online resource 6). Our data shed light on the role of gal3 as microglial-associated agent involved in $\mathrm{A} \beta$ aggregation.

\section{Discussion}

Recent findings suggest an important role of neuroinflammation in neurodegenerative diseases [18]. Thus, selective mutations in microglia/myeloid-specific genes, including the gene encoding TREM2, have been associated with $\mathrm{AD}$ [16]. Experimental AD studies have suggested that TREM2 is instrumental in neuroinflammation $[24,35]$ and drives DAM microglia [27, 30]. Gal3, a carbohydrate-binding protein, is one of the most upregulated genes associated with DAM [30, 34, 38]. Holtman et al. (2015) anticipated gal3 as a gene strongly related to microglial DAM phenotype [22]. To study the role of gal3 in AD pathogenesis, we have analyzed human brains from AD patients and 5xFAD mice lacking gal3. The main conclusions from our study are (1) gal3 protein is increased tenfold in human AD brains and is mostly restricted to plaque-associated microglia in humans and 5xFAD mice, (2) certain SNPs linked to the LGALS3 gene are associated with $\mathrm{AD},(3)$ gal 3 deficiency reduces $\mathrm{A} \beta$ plaque burden and the overall proinflammatory response and plaque size and improves cognitive performance in $5 \mathrm{xFAD} /$ Gal3KO mice, (4) gal3 is an endogenous TREM2 ligand, (5) gal 3 is released in response to $\mathrm{fA} \beta$ and (6) gal 3 interacts with $\mathrm{A} \beta$, affecting amyloid plaque morphology. Hence, gal3 emerges as a central upstream regulator of $\mathrm{AD}$-associated pathology.

Given the relationship between innate immune systemrelated genes and $\mathrm{AD}$ incidence $[18,19]$, deciphering how A $\beta$ aggregates trigger neuroinflammation is of critical importance. For this purpose, we first analyzed the role of gal 3 in the $A \beta$-induced inflammatory response in microglial cells. To this end, we took advantage of both chemical inhibition and gene deletion. Gal3 inhibition robustly reduced $\mathrm{fA} \beta$-induced iNOS expression in BV2 cells, an 

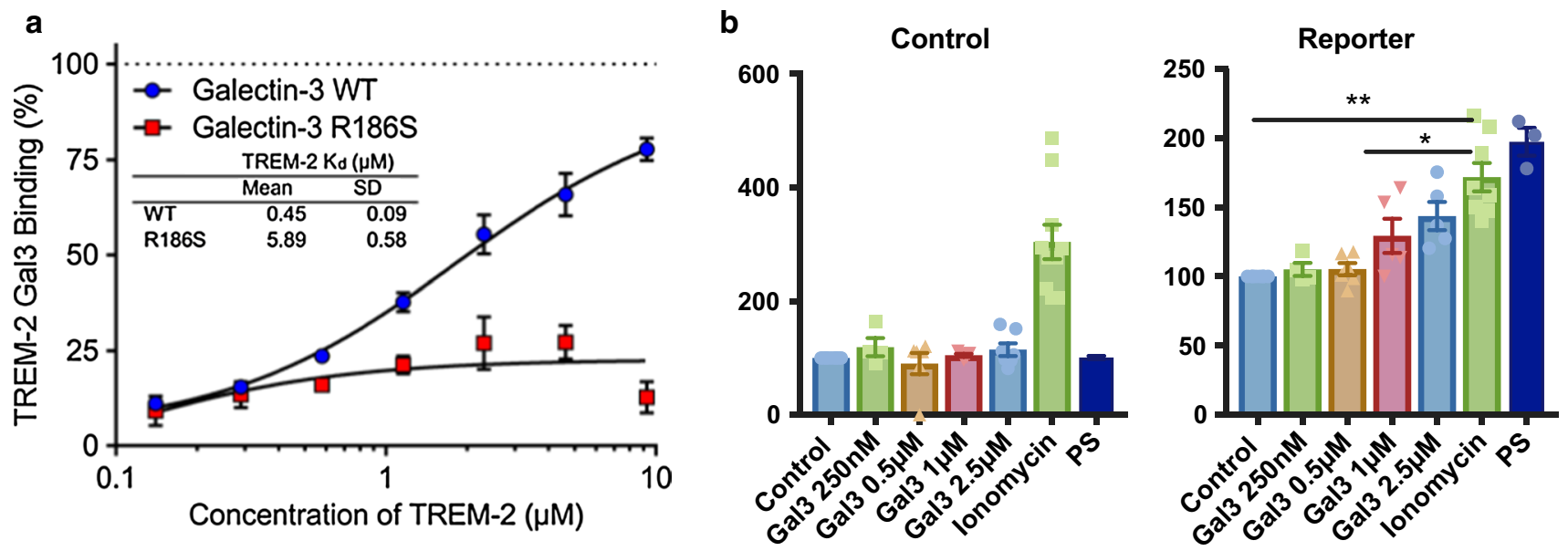

Fig. 6 Galectin-3 interacts with TREM2 through its carbohydratebinding domain. a Fluorescent anisotropy assay for galectin-3 (gal3)/ TREM2 interaction. Data are presented as \% of TREM2-gal3 binding (gal3, WT and mutant gal3 with deficient carbohydrate-binding domain, R186S) and fluorescent probe interaction, by increasing concentrations of TREM2, together with the calculated $K_{\mathrm{d}}$ values for the gal3/TREM2 interaction $(n=2)$. b Control and DAP12 reporter cell lines were stimulated with increasing concentrations of gal3 $(250 \mathrm{nM}-2.5 \mu \mathrm{M})$, ionomycin and phosphatidylserine (PS). Statistical significance was calculated by Student's $t$ test or one-way ANOVA with Bonferroni's post hoc test. *p<0.05; **p $<0.01$. Data are shown as mean $\pm \mathrm{SD}$ effect that was extended to proinflammatory cytokines, including TNF $\alpha$, IL6, IL8 and IL12, which we confirmed in primary microglia cultures from WT and Gal3KO mice. These data suggest that gal3 is a critical alarmin that amplifies the $A \beta$-induced proinflammatory response. Since inefficient clearance of $\mathrm{A} \beta$ may play a determinant role in $\mathrm{AD}$ pathogenesis [67], we analyzed the effect of gal3 in two major mechanisms involved in $A \beta$ clearance: $A \beta$ phagocytosis and IDE-1 levels, a key metalloprotease involved in $\mathrm{A} \beta$ degradation by microglia [48]. Gal3 was able to alter $A \beta$ phagocytosis in vitro showing a complex role of gal3 in $\mathrm{A} \beta$ phagocytosis depending on $\mathrm{A} \beta$ species (monomers or fibrils) or if pretreated or not (see suppl. Fig. 2e-f, online resource 2). Hence, further experiments are needed to clarify the exact role of gal 3 in the whole dynamic process of $A \beta$ phagocytosis and clearance. We found gal3 deficiency to increase IDE-1 levels in vitro and in vivo, suggesting a detrimental role of gal3 in A $\beta$ clearance. Supporting this, CSF levels of $\mathrm{A} \beta 42$ were significantly higher in $5 \mathrm{xFAD} / \mathrm{Gal} 3 \mathrm{KO}$ as compared with $5 \mathrm{xFAD}$. Overall, our study demonstrates an instrumental role of gal 3 in driving the $\mathrm{fA} \beta$-induced proinflammatory response and in contributing to a deleterious effect in $\mathrm{A} \beta$ clearance.

Recent transcriptomic analysis of microglia at the singlecell level has identified a common disease-associated microglia phenotype, which has been suggested to be driven by TREM2 and apoE [27, 30, 38]. Interestingly, Krasemann et al. (2017) identified gal3 as one of the most upregulated genes in plaque-associated microglia, supporting our findings in human AD brains and 5xFAD mice [30]. Recently, Yang et al. overexpressed TREM2 in 5xFAD mice (5xFAD/
TREM2) and found gal 3 as one of the main genes affected by TREM 2 overexpression [34], suggesting that gal3 plays an important role in microglial function under disease conditions. We generated $5 \mathrm{xFAD} / \mathrm{Gal} 3 \mathrm{KO}$ mice to answer whether gal3 plays a role in microglia-associated AD pathogenesis and to test if gal3 signaling is associated with TREM2. To answer this question, we performed an inflammatory gene array, demonstrating an age-dependent inflammatory response, involving complement components, chemokines, interleukin receptors, toll-like receptors and DAM genes in $5 x F A D$ mice. This inflammatory response was highly attenuated in $5 \mathrm{xFAD} / \mathrm{Gal} 3 \mathrm{KO}$ mice, thus confirming gal3 as a master regulator of $\mathrm{AD}$-associated brain immune responses. Pathway analysis in mice at 6 and 18 months of age identified TLR and DAP12, a TREM2 signaling adaptor protein, as one of the most significant pathways associated with gal3 in the $5 x F A D$ mice. This gene expression data suggest an important role of gal3 in the AD neuroinflammatory response, perhaps by stimulating NFkb-related regulators whereby TLR4, and/or other TLRs $[9,25]$ or glycoproteins, such as TREM2 [14, 65], are involved. Despite the clear connection between gal3-, TLR- and TREM2-related pathways, the regulation of these pathways is not known, and further experimentation is needed.

Consequently, we investigated whether gal3 interacts with TREM2, a key receptor that has been suggested as a driver of the DAM phenotype. Our confocal microscopy study demonstrated a remarkable cellular colocalization of TREM 2 and gal 3 in microglial cells around $A \beta$ plaques and a near $100 \%$ correspondence between both microglial markers, an indication that gal3 specifically labels DAM. 
Fig. 7 Galectin-3 induces the formation of insoluble $\mathrm{A} \beta$ aggregates following injections of $\mathrm{A} \beta$ monomers in the hippocampi of WT mice. A $\beta$ monomers were injected with galectin-3 (Gal3) $(\mathrm{A} \beta+\mathrm{Gal} 3)$ or without $(A \beta)$ after $1 \mathrm{~h} \mathrm{~A} \beta$ monomers incubation w/o gal3 into the right or left hippocampi of WT mice, respectively. a Staining for $A \beta$ and gal 3 in the left hippocampus (only $\mathrm{A} \beta$ monomers injected). $\mathbf{b}, \mathbf{c}$ Staining for $A \beta$ and gal 3 in the right hippocampus $(\mathrm{A} \beta+\mathrm{gal} 3$ injected). Dashed frames in $\mathbf{b}$ are magnified and shown in $\mathbf{c}$. d Thioflavin-S and A $\beta$ staining of the left hippocampus (only $\mathrm{A} \beta$ injected). $\mathrm{e}$ Thioflavin-S and $\mathrm{A} \beta$ staining of the right hippocampus (A $\beta+$ gal 3 injected). White arrows point to gal3 and thioflavin- $\mathrm{S}^{+}$aggregates. $\mathbf{f}, \mathbf{g}$ Iba1 and GFAP immunoreactivity in the right hippocampus $(\mathrm{A} \beta+$ gal 3 were injected $)$
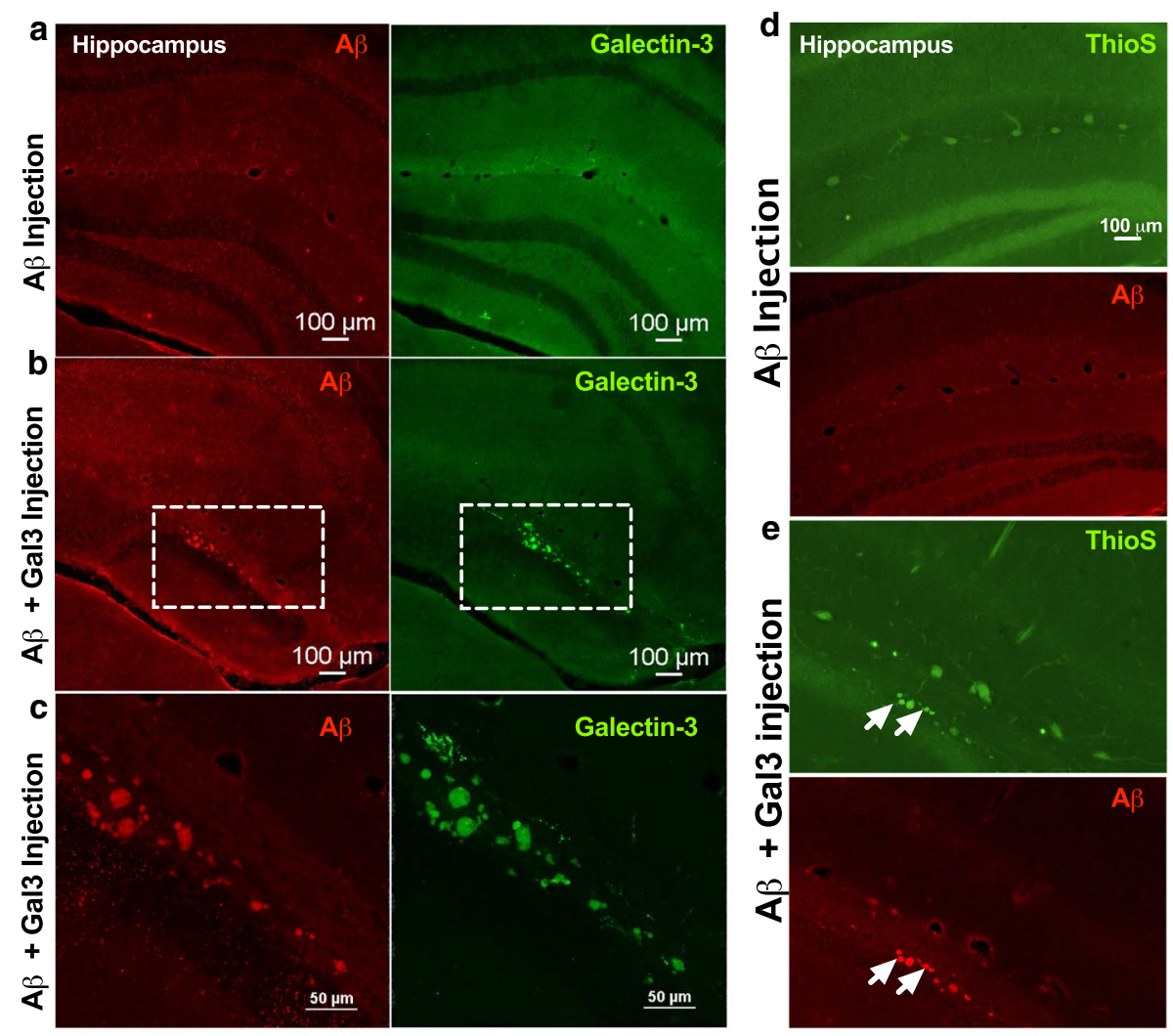

$A \beta+$ Gal3 injection
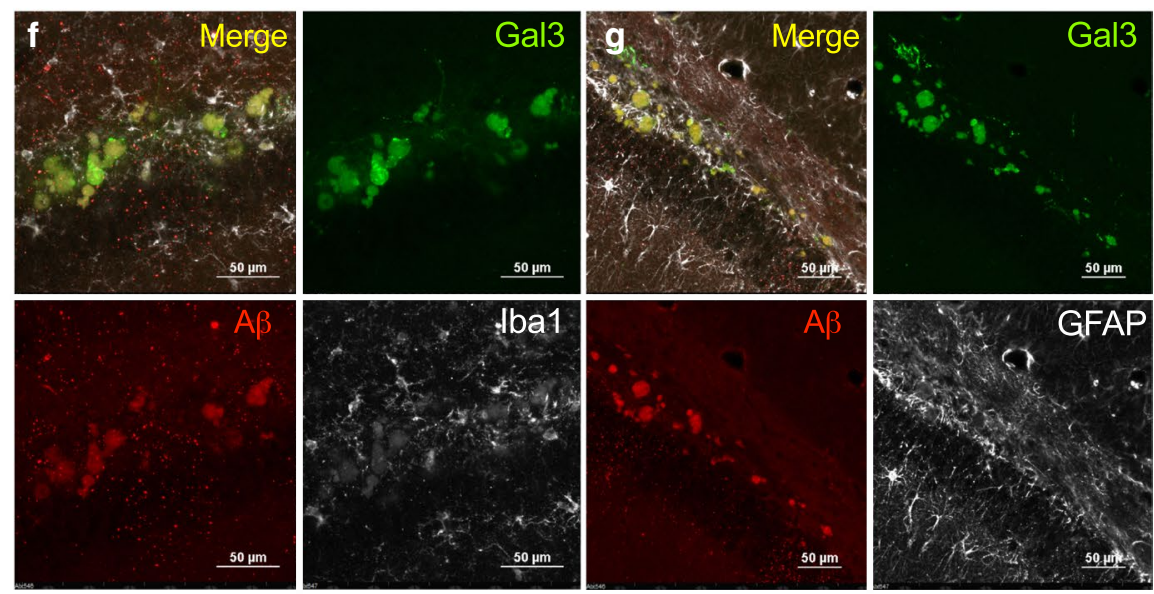

This view was further supported by Clec7a immunostaining, a recognized DAM marker. STORM microscopy demonstrated that TREM2 and gal3 physically interact on microglial processes, most likely at the cell membranes of DAM microglia. We also incubated sections from 5xFAD/ Gal3KO mice with recombinant gal3 to analyze the potential binding between TREM 2 and extracellular gal3. This assay demonstrated the ability of gal3 to selectively bind to TREM2 ${ }^{+}$microglia but not to homeostatic microglia. Direct interaction between gal3's carbohydrate recognition domain and TREM2 was demonstrated by fluorescent anisotropy with a $K_{\mathrm{d}}$ value of $450 \pm 90 \mathrm{nM}$, which was in the same range as other preferred glycoproteins $[11,12]$. The ability of gal 3 to stimulate TREM 2 was finally confirmed by a TREM2-DAP12 reporter cell line. Overall, our data suggest that the switch from homeostatic microglia to DAM is accompanied by significant upregulation of both TREM2 and gal3. Gal3 may thus bind to and activate different microglial receptors including TREM2 (present study), TLR4 [9], IGFR [33] and MerTK [43]. In fact, because gal3 is relatively promiscuous in its interactions with glycoproteins, it may be behind the chronic and detrimental activation of microglia in AD. Regardless of this possibility, what our 
study demonstrates is that the pleiotropic activity of gal3 drives important amyloid-associated immune responses.

Additionally, our study has uncovered an unexpected role of gal 3 as a powerful $A \beta$ binding agent. We have previously demonstrated the ability of LPS-induced reactive microglia to release gal3 [9, 64]. More recently, we have demonstrated a significant increase of gal3 levels in CSF from mice exposed to traumatic brain injury [64], an indication that gal3 is released by reactive microglia. In this study, we provide evidence that gal 3 is actively released by microglia in response to a fA $\beta$ challenge. In APP mice, gal 3 is present in the extracellular space and associated with amyloid fibrils (unpublished). Taken together, the possibility that gal3 directly interacts with $\mathrm{A} \beta$ to affect aggregation becomes plausible. To test this possibility, we incubated $A \beta$ monomers with or without gal 3 for $1 \mathrm{~h}$ at $37^{\circ} \mathrm{C}$ and injected $2 \mu \mathrm{l}$ of each condition into either the left or right hippocampi of WT mice. A ThT assay demonstrated $\mathrm{fA} \beta$ as the predominant form of $\mathrm{A} \beta$ present in both injections. $\mathrm{A} \beta$ deposition was analyzed 2 months after injections. While no $\mathrm{A} \beta$ deposition was found in animals injected with $\mathrm{A} \beta$ monomers alone, co-injection of $A \beta$ monomers and gal 3 resulted in evident insoluble $A \beta$ aggregates, suggesting that gal 3 is directly involved in $A \beta$ plaque formation. To our knowledge, this is the first report showing insoluble $A \beta$ aggregates long after $\mathrm{A} \beta$ brain injections in WT mice. Thus, Meyer-Luehmann et al. [40] injected brain homogenates from aged APP mice in the hippocampus of WT mice and found no evidence of $A \beta$ aggregates 4 months after injection. In contrast, injections of the same brain extracts in $\mathrm{AD}$ transgenic mice led to robust deposition of $A \beta[15,28,40,44]$. Further, repetitive $A \beta$ injections into the hippocampus of WT mice demonstrated that $\mathrm{A} \beta$ deposits are drastically reduced from day 1 to day 7 after injections [15].

Recently, Heneka et al. have demonstrated that ASC specks released from reactive microglia physically interact with $A \beta$, acting as an $A \beta$ cross-seeding agent [57]. Eliminating microglia has been shown to prevent plaque formation in APP transgenic mice [54], suggesting that factors released from microglia may seed amyloid plaques. Our study reinforces the view that reactive microglia play a critical role in $\mathrm{A} \beta$ plaque dynamics and associated immune responses by releasing $A \beta$ cross-seeding agents (i.e., ASC specks) and gal3. A $\beta$ plaque formation is believed to precede the appearance of clinical symptoms, so elucidating the earlier molecular mechanism involved in $\mathrm{A} \beta$ plaque formation appears critical for the establishment of early promising therapeutic strategies aiming at halting the development of $\mathrm{AD}$ early. Gal3-inhibition appears to be a promising $\mathrm{A} \beta$ therapeutic target. The ability of gal 3 to drive proinflammatory fA $\beta$-associated immune responses and hinder $A \beta$ clearance makes this protein a strategic upstream regulator of AD pathology. Indeed, the pathogenic role of gal3 was confirmed in adult $5 \times$ FAD mice lacking gal 3 as those mice had a significantly lower $\mathrm{A} \beta$ load and ameliorated cognitive/ spatial memory deficits, which was observed in the Morris water maze test.

Our results suggest that $L G A L S 3$ gene variants affect the risk of developing $\mathrm{AD}$, as indicated by the 5 SNPs in the $L G A L S 3$ gene that we found to be related to increased AD frequency. However, according to the GWAS catalogue (https://www.ebi.ac.uk/gwas/), none of the variants reported in suppl. Table 3 (online resource 10) or those in linkage disequilibrium with them (suppl. Fig. 3b, online resource 3), have been previously associated with $\mathrm{AD}$. This could be due to the fact that the GWAS approach requires large samples to detect modest effects, partly due to the multiple testing corrections applied. However, the impact of these LGALS3 SNPs appears to be similar to other SNPs included in the GWAS, supporting a role for this gene in the development of AD. Our meta-analysis only comprised those SNPs belonging to a linkage disequilibrium block located at the 5 '-end of the $L G A L S 3$ gene, therefore, we do not know if other regions have genetic variants that could lead to stronger effects. At present it is difficult to speculate in what way the SNPs of gal3 is altering the function or expression of the protein. Further replication studies covering the entire genetic region of this locus will be necessary to confirm our results.

\section{Conclusions}

In conclusion, we provide evidence that gal3 is a central upstream regulator of the microglial immune response in $\mathrm{AD}$. It drives proinflammatory activation of microglia in response to fA $\beta$ along with impairment of fA $\beta$ degradation and clearance. Our study has additionally uncovered another exciting feature of gal3 disease biology that appears important in AD pathogenesis. Gal3 plays a role as an endogenous TREM2 ligand, a key receptor driving microglial activation in $\mathrm{AD}$. As a result, gal3 inhibition may be a potential pharmacological approach to counteract $\mathrm{AD}$.

Acknowledgements This work was supported by Grants from the Swedish Research Council, and the Strong Research Environment MultiPark (Multidisciplinary Research in Parkinson's and Alzheimer's Disease at Lund University), Bagadilico (Linné consortium sponsored by the Swedish Research Council), the Swedish Alzheimer's Foundation, Swedish Brain Foundation, A.E. Berger Foundation, Gyllenstiernska Krapperup Foundation, the Royal Physiographic Society, Crafoord Foundation, Olle Engkvist Byggmästare Foundation, Wiberg Foundation, G\&J Kock Foundation, Stohnes Foundation, Swedish Dementia Association and the Medical Faculty at Lund University. This work was supported by Grant SAF2015-64171R (Spanish MINECO/FEDER, UE), by Instituto de Salud Carlos III (ISCiii) of Spain, co-financed by FEDER funds from European Union through grants PI15/00796 and PI18/01557 (to AG), PI15/00957 and PI18/01556 (to JV), and CIBERNED (to AG and JV), by Consejería de Economía, Innovación, Ciencia y Empleo, Junta de Andalucia Proyecto de Excelencia (CTS2035) (to JV and AG), and by Malaga University grant PPIT.UMA. 
B1.2017/26 (to RSV). AV and GCB received funding from the Innovative Medicines Initiative 2 Joint Undertaking under Grant agreement no. 115976 (PHAGO). CIBERNED "Centro de Investigacion Biomedica en Red sobre Enfermedades Neurodegenerativas (CIBERNED), Madrid (Spain)". HL and AF were supported by the Swedish Research Council, the Swedish Brain Foundation, the Alzheimer Foundation and the Åhlén Foundation. UJN was supported by Grants from the Knut and Alice Wallenberg Foundation (KAW 2013.0022) and the Swedish Research Council (Grant no. 621-2012-2978). We thank Barbro-Kahl Knutson for help with producing and analyzing galectins, and Fredrik Zetterberg and Hans Schambye at Galecto Biotech AB, Sweden, for providing galectin inhibitors.

Author contributions A.B-S., T.D., R.R., R.S-V., A.P., I.F-J., Y.Y., M.W., A.V., D.A., C.D., J.S., S.J., V.N-G., J.G., L.M.R., and S.L. performed experiments and analyzed data. M.W. and E.E. provided human samples. A.B-S., G.C.B., T.D., J.L.V and J.V. were involved in the study design and wrote the paper. All authors discussed results and commented on the manuscript.

\section{Compliance with ethical standards}

Conflict of interest Ulf J. Nilsson and Hakon Leffler are shareholders in Galecto Biotech $\mathrm{AB}$, Sweden, which develops galectin inhibitors towards clinical use.

Open Access This article is distributed under the terms of the Creative Commons Attribution 4.0 International License (http://creativeco mmons.org/licenses/by/4.0/), which permits unrestricted use, distribution, and reproduction in any medium, provided you give appropriate credit to the original author(s) and the source, provide a link to the Creative Commons license, and indicate if changes were made.

\section{References}

1. Alam Q, Alam MZ, Mushtaq G, Damanhouri GA, Rasool M, Kamal MA et al (2016) Inflammatory process in Alzheimer's and Parkinson's diseases: central role of cytokines. Curr Pharm Des 22:541-548

2. Antunez C, Boada M, Gonzalez-Perez A, Gayan J, Ramirez-Lorca $\mathrm{R}$, Marin J et al (2011) The membrane-spanning 4-domains, subfamily A (MS4A) gene cluster contains a common variant associated with Alzheimer's disease. Genome Med 3:33. https://doi. org/10.1186/gm249

3. Bachiller S, Rybkina T, Porras-Garcia E, Perez-Villegas E, Tabares L, Armengol JA et al (2015) The HERC1 E3 ubiquitin ligase is essential for normal development and for neurotransmission at the mouse neuromuscular junction. Cell Mol Life Sci 72:29612971. https://doi.org/10.1007/s00018-015-1878-2

4. Ballard C, Gauthier S, Corbett A, Brayne C, Aarsland D, Jones E (2011) Alzheimer's disease. Lancet 377:1019-1031. https://doi. org/10.1016/s0140-6736(10)61349-9

5. Barrett JC, Fry B, Maller J, Daly MJ (2005) Haploview: analysis and visualization of LD and haplotype maps. Bioinformatics 21:263-265. https://doi.org/10.1093/bioinformatics/bth457

6. Bejanin A, Schonhaut DR, La Joie R, Kramer JH, Baker SL, Sosa $\mathrm{N}$ et al (2017) Tau pathology and neurodegeneration contribute to cognitive impairment in Alzheimer's disease. Brain 140:32863300. https://doi.org/10.1093/brain/awx243

7. Bettens K, Sleegers K, Van Broeckhoven C (2013) Genetic insights in Alzheimer's disease. Lancet Neurol 12:92-104. https ://doi.org/10.1016/S1474-4422(12)70259-4
8. Boada M, Antunez C, Ramirez-Lorca R, DeStefano AL, Gonzalez-Perez A, Gayan J et al (2014) ATP5H/KCTD2 locus is associated with Alzheimer's disease risk. Mol Psychiatry 19:682-687. https://doi.org/10.1038/mp.2013.86

9. Burguillos MA, Svensson M, Schulte T, Boza-Serrano A, Garcia-Quintanilla A, Kavanagh E et al (2015) Microglia-secreted galectin-3 acts as a toll-like receptor 4 ligand and contributes to microglial activation. Cell Rep. https://doi.org/10.1016/j.celre p.2015.02.012

10. Butovsky O, Weiner HL (2018) Microglial signatures and their role in health and disease. Nat Rev Neurosci 19:622-635. https ://doi.org/10.1038/s41583-018-0057-5

11. Carlsson MC, Bengtson P, Cucak H, Leffler H (2013) Galectin-3 guides intracellular trafficking of some human serotransferrin glycoforms. J Biol Chem 288:28398-28408. https://doi. org/10.1074/jbc.M113.487793

12. Carlsson MC, Cederfur C, Schaar V, Balog CI, Lepur A, Touret F et al (2011) Galectin-1-binding glycoforms of haptoglobin with altered intracellular trafficking, and increase in metastatic breast cancer patients. PLoS One 6:e26560. https://doi. org/10.1371/journal.pone.0026560

13. Carlsson S, Oberg CT, Carlsson MC, Sundin A, Nilsson UJ, Smith D et al (2007) Affinity of galectin-8 and its carbohydrate recognition domains for ligands in solution and at the cell surface. Glycobiology 17:663-676. https://doi.org/10.1093/glyco $\mathrm{b} / \mathrm{cwm} 026$

14. Colonna M, Wang Y (2016) TREM2 variants: new keys to decipher Alzheimer disease pathogenesis. Nat Rev Neurosci 17:201207. https://doi.org/10.1038/nrn.2016.7

15. Faucher P, Mons N, Micheau J, Louis C, Beracochea DJ (2015) Hippocampal injections of oligomeric amyloid beta-peptide (1-42) induce selective working memory deficits and long-lasting alterations of ERK signaling pathway. Front Aging Neurosci 7:245. https://doi.org/10.3389/fnagi.2015.00245

16. Guerreiro R, Wojtas A, Bras J, Carrasquillo M, Rogaeva E, Majounie $\mathrm{E}$ et al (2013) TREM2 variants in Alzheimer's disease. N Engl J Med 368:117-127. https://doi.org/10.1056/NEJMoa1211851

17. Guillot-Sestier MV, Doty KR, Gate D, Rodriguez J Jr, Leung BP, Rezai-Zadeh K et al (2015) Il10 deficiency rebalances innate immunity to mitigate Alzheimer-like pathology. Neuron 85:534 548. https://doi.org/10.1016/j.neuron.2014.12.068

18. Heneka MT, Carson MJ, Khoury JE, Landreth GE, Brosseron F et al (2015) Neuroinflammation in Alzheimer's disease. Lancet Neurol 14:388-405. https://doi.org/10.1016/s1474 $-4422(15) 70016-5$

19. Heneka MT, Kummer MP, Latz E (2014) Innate immune activation in neurodegenerative disease. Nat Rev Immunol 14:463-477. https://doi.org/10.1038/nri3705

20. Heneka MT, Kummer MP, Stutz A, Delekate A, Schwartz S, Vieira-Saecker A et al (2013) NLRP3 is activated in Alzheimer's disease and contributes to pathology in APP/PS1 mice. Nature 493:674-678. https://doi.org/10.1038/nature11729

21. Hinrichs AS, Karolchik D, Baertsch R, Barber GP, Bejerano G, Clawson $\mathrm{H}$ et al (2006) The UCSC genome browser database: update 2006. Nucleic Acids Res 34:D590-D598. https://doi. org/10.1093/nar/gkj144

22. Holtman IR, Raj DD, Miller JA, Schaafsma W, Yin Z, Brouwer $\mathrm{N}$ et al (2015) Induction of a common microglia gene expression signature by aging and neurodegenerative conditions: a coexpression meta-analysis. Acta Neuropathol Commun 3:31. https ://doi.org/10.1186/s40478-015-0203-5

23. Hsieh CL, Koike M, Spusta SC, Niemi EC, Yenari M, Nakamura $\mathrm{MC}$ et al (2009) A role for TREM2 ligands in the phagocytosis of apoptotic neuronal cells by microglia. J Neurochem 109:11441156. https://doi.org/10.1111/j.1471-4159.2009.06042.x 
24. Jay TR, Miller CM, Cheng PJ, Graham LC, Bemiller S, Broihier ML et al (2015) TREM2 deficiency eliminates TREM2+ inflammatory macrophages and ameliorates pathology in Alzheimer's disease mouse models. J Exp Med 212:287-295. https://doi. org/10.1084/jem.20142322

25. Jin JJ, Kim HD, Maxwell JA, Li L, Fukuchi K (2008) Toll-like receptor 4-dependent upregulation of cytokines in a transgenic mouse model of Alzheimer's disease. J Neuroinflamm 5:23. https ://doi.org/10.1186/1742-2094-5-23

26. Karolchik D, Hinrichs AS, Furey TS, Roskin KM, Sugnet CW, Haussler D et al (2004) The UCSC table browser data retrieval tool. Nucleic Acids Res 32:D493-D496. https://doi. org/10.1093/nar/gkh103

27. Keren-Shaul H, Spinrad A, Weiner A, Matcovitch-Natan O, Dvir-Szternfeld R, Ulland TK et al (2017) A unique microglia type associated with restricting development of Alzheimer's disease. Cell 169(1276-1290):e1217. https://doi.org/10.1016/j. cell.2017.05.018

28. Kim HY, Lee DK, Chung BR, Kim HV, Kim Y (2016) Intracerebroventricular injection of amyloid-beta peptides in normal mice to acutely induce Alzheimer-like cognitive deficits. J Vis Exp. https://doi.org/10.3791/53308

29. Kober DL, Alexander-Brett JM, Karch CM, Cruchaga C, Colonna M, Holtzman MJ et al (2016) Neurodegenerative disease mutations in TREM2 reveal a functional surface and distinct loss-of-function mechanisms. Elife. https://doi.org/10.7554/elife .20391

30. Krasemann S, Madore C, Cialic R, Baufeld C, Calcagno N, El Fatimy R et al (2017) The TREM2-APOE pathway drives the transcriptional phenotype of dysfunctional microglia in neurodegenerative diseases. Immunity 47(566-581):e569. https://doi. org/10.1016/j.immuni.2017.08.008

31. Kummer MP, Hermes M, Delekarte A, Hammerschmidt T, Kumar S, Terwel D et al (2011) Nitration of tyrosine 10 critically enhances amyloid beta aggregation and plaque formation. Neuron 71:833-844. https://doi.org/10.1016/j.neuron.2011.07.001

32. Kummer MP, Hulsmann C, Hermes M, Axt D, Heneka MT (2012) Nitric oxide decreases the enzymatic activity of insulin degrading enzyme in APP/PS1 mice. J Neuroimmune Pharmacol 7:165-172. https://doi.org/10.1007/s11481-011-9339-7

33. Lalancette-Hebert M, Swarup V, Beaulieu JM, Bohacek I, Abdelhamid E, Weng YC et al (2012) Galectin-3 is required for resident microglia activation and proliferation in response to ischemic injury. J Neurosci 32:10383-10395. https://doi.org/10.1523/ JNEUROSCI.1498-12.2012

34. Lee CYD, Daggett A, Gu X, Jiang LL, Langfelder P, Li X et al (2018) Elevated TREM2 gene dosage reprograms microglia responsivity and ameliorates pathological phenotypes in Alzheimer's disease models. Neuron 97(1032-1048):e1035. https://doi. org/10.1016/j.neuron.2018.02.002

35. Leyns CEG, Ulrich JD, Finn MB, Stewart FR, Koscal LJ, Remolina Serrano J et al (2017) TREM2 deficiency attenuates neuroinflammation and protects against neurodegeneration in a mouse model of tauopathy. Proc Natl Acad Sci USA 114:11524-11529. https://doi.org/10.1073/pnas.1710311114

36. Li H, Wetten S, Li L, St Jean PL, Upmanyu R, Surh L et al (2008) Candidate single-nucleotide polymorphisms from a genomewide association study of Alzheimer disease. Arch Neurol 65:45-53. https://doi.org/10.1001/archneurol.2007.3

37. Martinez-Mir A, Gonzalez-Perez A, Gayan J, Antunez C, Marin J, Boada M et al (2013) Genetic study of neurexin and neuroligin genes in Alzheimer's disease. J Alzheimers Dis 35:403-412. https ://doi.org/10.3233/JAD-122257

38. Mathys H, Adaikkan C, Gao F, Young JZ, Manet E, Hemberg $M$ et al (2017) Temporal tracking of microglia activation in neurodegeneration at single-cell resolution. Cell Rep 21:366-380. https://doi.org/10.1016/j.celrep.2017.09.039

39. Mazaheri F, Snaidero N, Kleinberger G, Madore C, Daria A, Werner $G$ et al (2017) TREM2 deficiency impairs chemotaxis and microglial responses to neuronal injury. EMBO Rep 18:11861198. https://doi.org/10.15252/embr.201743922

40. Meyer-Luehmann M, Coomaraswamy J, Bolmont T, Kaeser S, Schaefer C, Kilger E et al (2006) Exogenous induction of cerebral beta-amyloidogenesis is governed by agent and host. Science 313:1781-1784. https://doi.org/10.1126/science.1131864

41. Mueller SG, Weiner MW, Thal LJ, Petersen RC, Jack CR, Jagust W et al (2005) Ways toward an early diagnosis in Alzheimer's disease: the Alzheimer's Disease Neuroimaging Initiative (ADNI). Alzheimers Dement 1:55-66. https://doi.org/10.1016/j. jalz.2005.06.003

42. Nelson PT, Head E, Schmitt FA, Davis PR, Neltner JH, Jicha GA et al (2011) Alzheimer's disease is not "brain aging": neuropathological, genetic, and epidemiological human studies. Acta Neuropathol 121:571-587. https://doi.org/10.1007/s00401-011-0826-y

43. Nomura K, Vilalta A, Allendorf DH, Hornik TC, Brown GC (2017) Activated microglia desialylate and phagocytose cells via neuraminidase, galectin-3, and mer tyrosine kinase. J Immunol 198:4792-4801. https://doi.org/10.4049/jimmunol.1502532

44. Parhizkar S, Arzberger T, Brendel M, Kleinberger G, Deussing $M$, Focke $C$ et al (2019) Loss of TREM2 function increases amyloid seeding but reduces plaque-associated ApoE. Nat Neurosci 22:191-204. https://doi.org/10.1038/s41593-018-0296-9

45. Peterson K, Kumar R, Stenstrom O, Verma P, Verma PR, Hakansson $\mathrm{M}$ et al (2018) Systematic tuning of fluoro-galectin-3 interactions provides thiodigalactoside derivatives with single-digit $\mathrm{nM}$ affinity and high selectivity. J Med Chem 61:1164-1175. https:// doi.org/10.1021/acs.jmedchem.7b01626

46. Prokop S, Miller KR, Heppner FL (2013) Microglia actions in Alzheimer's disease. Acta Neuropathol 126:461-477. https://doi. org/10.1007/s00401-013-1182-x

47. Purcell S, Neale B, Todd-Brown K, Thomas L, Ferreira MA, Bender D et al (2007) PLINK: a tool set for whole-genome association and population-based linkage analyses. Am J Hum Genet 81:559-575. https://doi.org/10.1086/519795

48. Qiu WQ, Walsh DM, Ye Z, Vekrellis K, Zhang J, Podlisny MB et al (1998) Insulin-degrading enzyme regulates extracellular levels of amyloid beta-protein by degradation. J Biol Chem 273:32730-32738

49. Salomonsson E, Carlsson MC, Osla V, Hendus-Altenburger R, Kahl-Knutson B, Oberg CT, Sundin A, Nilsson R et al (2010) Mutational tuning of galectin-3 specificity and biological function. J Biol Chem 285:35079-35091. https://doi.org/10.1074/jbc. M109.098160

50. Salomonsson E, Larumbe A, Tejler J, Tullberg E, Rydberg H, Sundin A et al (2010) Monovalent interactions of galectin-1. Biochemistry 49:9518-9532. https://doi.org/10.1021/bi1009584

51. Sanchez-Varo R, Trujillo-Estrada L, Sanchez-Mejias E, Torres M, Baglietto-Vargas D, Moreno-Gonzalez I et al (2012) Abnormal accumulation of autophagic vesicles correlates with axonal and synaptic pathology in young Alzheimer's mice hippocampus. Acta Neuropathol 123:53-70. https://doi.org/10.1007/s0040 1-011-0896-x

52. Sorme P, Arnoux P, Kahl-Knutsson B, Leffler H, Rini JM, Nilsson UJ (2005) Structural and thermodynamic studies on cation-Pi interactions in lectin-ligand complexes: high-affinity galectin-3 inhibitors through fine-tuning of an arginine-arene interaction. J Am Chem Soc 127:1737-1743. https://doi.org/10.1021/ja043475p

53. Sorme P, Kahl-Knutsson B, Huflejt M, Nilsson UJ, Leffler H (2004) Fluorescence polarization as an analytical tool to evaluate galectin-ligand interactions. Anal Biochem 334:36-47. https:// doi.org/10.1016/j.ab.2004.06.042 
54. Sosna J, Philipp S, Albay R III, Reyes-Ruiz JM, Baglietto-Vargas D, LaFerla FM, Glabe CG (2018) Early long-term administration of the CSF1R inhibitor PLX3397 ablates microglia and reduces accumulation of intraneuronal amyloid, neuritic plaque deposition and pre-fibrillar oligomers in 5XFAD mouse model of Alzheimer's disease. Mol Neurodegener 13:11. https://doi.org/10.1186/ s13024-018-0244-X

55. Trujillo-Estrada L, Davila JC, Sanchez-Mejias E, Sanchez-Varo R, Gomez-Arboledas A, Vizuete M et al (2014) Early neuronal loss and axonal/presynaptic damage is associated with accelerated amyloid-beta accumulation in AbetaPP/PS1 Alzheimer's disease mice subiculum. J Alzheimers Dis 42:521-541. https:// doi.org/10.3233/JAD-140495

56. van der Zwaag D, Vanparijs N, Wijnands S, De Rycke R, De Geest BG, Albertazzi L (2016) Super resolution imaging of nanoparticles cellular uptake and trafficking. ACS Appl Mater Interfaces 8:6391-6399. https://doi.org/10.1021/acsami.6b00811

57. Venegas C, Kumar S, Franklin BS, Dierkes T, Brinkschulte R, Tejera D et al (2017) Microglia-derived ASC specks cross-seed amyloid-beta in Alzheimer's disease. Nature 552:355-361. https ://doi.org/10.1038/nature25158

58. Wang Q, Yu X, Li L, Zheng J (2014) Inhibition of amyloidbeta aggregation in Alzheimer's disease. Curr Pharm Des 20:1223-1243

59. Wang Y, Cella M, Mallinson K, Ulrich JD, Young KL, Robinette ML et al (2015) TREM2 lipid sensing sustains the microglial response in an Alzheimer's disease model. Cell 160:1061-1071. https://doi.org/10.1016/j.cell.2015.01.049

60. Wijsman EM, Pankratz ND, Choi Y, Rothstein JH, Faber KM, Cheng R et al (2011) Genome-wide association of familial late-onset Alzheimer's disease replicates BIN1 and CLU and nominates CUGBP2 in interaction with APOE. PLoS Genet 7:e1001308. https://doi.org/10.1371/journal.pgen.1001308
61. Xia J, Gill EE, Hancock RE (2015) NetworkAnalyst for statistical, visual and network-based meta-analysis of gene expression data. Nat Protoc 10:823-844. https://doi.org/10.1038/nprot.2015.052

62. Xiang X, Werner G, Bohrmann B, Liesz A, Mazaheri F, Capell A et al (2016) TREM2 deficiency reduces the efficacy of immunotherapeutic amyloid clearance. EMBO Mol Med 8:992-1004. https://doi.org/10.15252/emmm.201606370

63. Yin Z, Raj D, Saiepour N, Van Dam D, Brouwer N, Holtman IR et al (2017) Immune hyperreactivity of Abeta plaque-associated microglia in Alzheimer's disease. Neurobiol Aging 55:115-122. https://doi.org/10.1016/j.neurobiolaging.2017.03.021

64. Yip PK, Carrillo-Jimenez A, King P, Vilalta A, Nomura K, Chau CC et al (2017) Galectin-3 released in response to traumatic brain injury acts as an alarmin orchestrating brain immune response and promoting neurodegeneration. Sci Rep 7:41689. https://doi. org/10.1038/srep41689

65. Yuan P, Condello C, Keene CD, Wang Y, Bird TD, Paul SM et al (2016) TREM2 haplodeficiency in mice and humans impairs the microglia barrier function leading to decreased amyloid compaction and severe axonal dystrophy. Neuron 90:724-739. https://doi. org/10.1016/j.neuron.2016.05.003

66. Zhong L, Chen XF, Wang T, Wang Z, Liao C, Wang Z et al (2017) Soluble TREM2 induces inflammatory responses and enhances microglial survival. J Exp Med 214:597-607. https:// doi.org/10.1084/jem.20160844

67. Zuroff L, Daley D, Black KL, Koronyo-Hamaoui M (2017) Clearance of cerebral Abeta in Alzheimer's disease: reassessing the role of microglia and monocytes. Cell Mol Life Sci 74:2167-2201. https://doi.org/10.1007/s00018-017-2463-7

Publisher's Note Springer Nature remains neutral with regard to jurisdictional claims in published maps and institutional affiliations.

\section{Affiliations}

\section{Antonio Boza-Serrano' ${ }^{1}$ - Rocío Ruiz ${ }^{2}$. Raquel Sanchez-Varo ${ }^{3,13}$ • Juan García-Revilla ${ }^{2}$ Y Yiyi Yang ${ }^{1}$. Itzia Jimenez-Ferrer ${ }^{11}$ - Agnes Paulus ${ }^{1} \cdot$ Malin Wennström ${ }^{5} \cdot$ Anna Vilalta $^{4} \cdot$ David Allendorf $^{4} \cdot$ Jose Carlos Davila $^{3,13}$. John Stegmayr ${ }^{9}$. Sebastian Jiménez ${ }^{2,13}$. Maria A. Roca-Ceballos ${ }^{2}$. Victoria Navarro-Garrido ${ }^{2,13}$. Maria Swanberg ${ }^{11}$. Christine L. Hsieh ${ }^{12}$. Luis M. Real ${ }^{7}$. Elisabet Englund ${ }^{8}$. Sara Linse ${ }^{6}$. Hakon Leffler ${ }^{9}$. Ulf J. Nilsson ${ }^{10}$. Guy C. Brown ${ }^{4}$. Antonia Gutierrez $^{3,13}$. Javier Vitorica ${ }^{2,13}$. Jose Luis Venero ${ }^{2} \cdot$ Tomas Deierborg $^{1}$}

1 Department of Experimental Medical Science, Experimental Neuroinflammation Laboratory, Lund University, 22184 Lund, Sweden

2 Departamento de Bioquímica y Biología Molecular, Instituto de Biomedicina de Sevilla (IBiS, HUVR/CSIC/Universidad de Sevilla), Universidad de Sevilla, Seville, Spain

3 Departamento de Biología Celular, Genética y Fisiología, Instituto de Investigación Biomédica de Málaga (IBIMA), Facultad de Ciencias, Universidad de Málaga, Málaga, Spain

4 Department of Biochemistry, University of Cambridge, Cambridge, UK

5 Clinical Memory Research Unit, Department of Clinical Sciences Malmö, Lund University, Malmö, Sweden

6 Department of Biochemistry and Structural Biology, Lund University, Lund, Sweden

7 Unidad Clínica de Enfermedades Infecciosas y Microbiología, Hospital Universitario de Valme, Seville, Spain
8 Division of Oncology and Pathology, Department of Clinical Sciences, Lund University, Lund, Sweden

9 Department of Laboratory Medicine, Division of Microbiology, Immunology and Glycobiology (MIG), Lund University, Lund, Sweden

10 Department of Chemistry, Centre for Analysis and Synthesis, Lund University, Lund, Sweden

11 Translational Neurogenetics Unit, Department of Experimental Medical Science, Wallenberg Neuroscience Center, Lund University, 22184 Lund, Sweden

12 Immunology Section, Department of Medicine, San Francisco VA Medical Center, UCSF School of Medicine, 4150 Clement St. 111R, San Francisco, CA 94121, USA

13 Centro de Investigación Biomédica en Red sobre Enfermedades Neurodegenerativas (CIBERNED), Madrid, Spain 